\title{
AN END OF SERVICE LIFE ASSESSMENT OF PMMA LENSES FROM VETERAN CONCENTRATOR PHOTOVOLTAIC SYSTEMS
}

David C. Miller, ${ }^{1}$ Hussameldin I. Khonkar, ${ }^{2}$ Rebeca Herrero, ${ }^{3}$ Ignacio Antón, ${ }^{3}$ David K. Johnson, ${ }^{4}$ Thorsten Hornung, ${ }_{5}^{5}$ Tobias Schmid-Schirling, ${ }^{5}$ Todd B. Vinzant, ${ }^{4}$ Steve Deutch, ${ }^{4}$ Bobby To, ${ }^{1}$ Gabriel Sala, ${ }^{3}$ and Sarah $R$. Kurtz $^{1}$

${ }^{1}$ National Center for Photovoltaics, National Renewable Energy Laboratory (NREL), Golden, CO, USA

${ }^{2}$ Water and Energy Research Institute, King Abdulaziz City for Science and Technology (KACST), Riyadh, Saudi Arabia

${ }^{3}$ Instituto de Energía Solar - Universidad Politécnica de Madrid (IES-UPM), Madrid, Spain

${ }^{4}$ Biosciences Center, National Renewable Energy Laboratory, Golden, CO, USA

${ }^{5}$ Fraunhofer Institute for Solar Energy Systems (Fraunhofer ISE), Heidenhofstrasse 2, 79110 Freiburg, Germany

* Corresponding author: David.Miller@nrel.gov +1-303-384-7855 http://www.nrel.gov/pv/performance_reliability/

ABSTRACT

The optical performance of poly(methyl methacrylate) lenses from veteran concentrator photovoltaic modules was examined after the end of their service life. Lenses from the Martin-Marietta and Intersol module designs were examined from the "Solar Village" site near Riyadh, Saudi Arabia, as well as the Phoenix Sky Harbor airport, followed by the Arizona Public Service Solar Test and Research (APS-STaR) center in Tempe, Arizona. The various lens specimens were deployed for 20, 27, and 22 years, respectively. Optical characterizations included lens efficiency (Solar Simulator instrument), material transmittance and haze (of coupons cut from veteran lenses, then measured again after their faceted back surface was polished, and then measured again after the incident front surface was polished), and direct transmittance (as a function of detector's acceptance angle, using the Very Low Angular Beam Spread ("VLABS") instrument). Lens efficiency measurements compared the central region to the entire lens, also using hot and cold mirror measurements to diagnose differences in performance. A series of subsequent characterizations was performed because a decrease in performance of greater than $10 \%$ was observed for some of the veteran lenses. The optimal focal distance of the lenses was quantified using the Solar Simulator, and then correlated to lens curvature using a recently developed measurement technique. Surface roughness was examined using atomic force microscopy and scanning electron microscopy. Facet geometry (tip and valley radius) was quantified on cross-sectioned specimens. Molecular weight was compared between the incident and faceted surfaces of the lenses.

KEYWORDS

AFM, CPV durability, Fresnel lens, PMMA, SEM, reliability 


\section{INTRODUCTION \\ 1.1 MOTIVATION}

Concentrator photovoltaic (CPV) systems may use a refractive optical component, such as a Fresnel lens, to focus the direct solar flux onto a photovoltaic (PV) cell [1]. CPV uses high-efficiency cells and reduces cost by replacing large-area solar cells with less-expensive optical components. To realize a low levelized cost of electricity, the optical components must provide good performance over the desired service life of at least 25 years. Although the advancement of high-efficiency PV cells (such as multijunction III-V technology) has recently motivated interest in $\mathrm{CPV}$, an understanding of the reliability of the optical components remains limited.

Many of the recently proposed CPV systems use a Fresnel lens. This may consist of a monolithically constructed lens composed of poly(methyl methacrylate) (PMMA), a silicone-on-glass (SoG) laminated composite, or a PMMA-on-glass (PoG) laminated composite [2]. Factors including weight, optical performance [3], and attachment of the lens affect the CPV module design and its subsequent cost. A strong motivation therefore exists for selecting the appropriate type(s) of lens suitable for extended outdoor deployment.

\subsection{LITERATURE REVIEW: VETERAN CPV INSTALLATIONS}

Recent studies of the durability of CPV lens technology include Refs. [4,5,6,7], and the subject has been reviewed in Refs. [2,8]. Relevant topics include the degradation of the component material(s), chemical corrosion, mechanical fracture, mechanical fatigue, delamination, physical aging (visco-elastic flow and shape change), solid erosion (abrasion and wear) of the field-exposed surface, soiling (the accumulation of airborne contamination), and solarization (change in the optical performance based on the redox balance within glass) [2]. Material degradation may occur as the result of ultraviolet (UV) radiation, temperature, and/or moisture. Chemical corrosion may occur as the result of airborne species, including: acidic (or basic) rain, industrial chemicals, or ozone. Many of the durability studies in the literature focus on material-specific issues, especially optical performance.

Regarding the literature, one topic that remains relatively unexplored is the performance and characteristics of lenses from veteran sites. The "Solar Village" site near Riyadh, Saudi Arabia, was originally

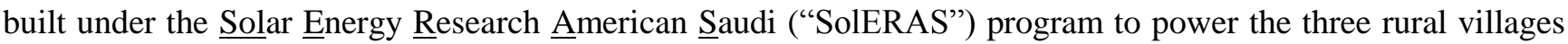
of Al-Hajrah, Al-Uyaynah, and Al-Jubaiah $[11,12,13,14,15,16,17,18,19,20,21,22,23,24,25]$. Of the 
aforementioned literature, Refs. [16,22,23] give a comprehensive description of the project history, including the operation, performance, reliability, and subsequent modifications to the system. The Solar Village site was the world's first large CPV system - ultimately including $350 \mathrm{~kW}$ of Martin-Marietta (M-M) Corporation CPV modules, 1.6 MWh of lead-acid batteries, and four 250-KVA standby diesel generators. The history of the system includes a variety of operating configurations, including: when it was first commissioned as a standalone power plant in November 1981; then connected to the Saudi national grid in September 1984; and then incorporated into the King Abdulaziz City for Science and Technology (KACST) in 1986. The system consisted of eight sub-fields of twenty 2-axis trackers, with 64 lens parquets per tracker (10,240 total lenses, from the four lens parquets). The trackers were automatically stowed (face down): from sunset to sunrise, on rainy days, and during dust storms. The modules were cleaned monthly using pressurized deionized water (with no physical contact) (first three years), then cleaned quarterly after the Solar Village system was connected to the grid. The majority of the system was stowed face down in 2001, upon achieving its designated 20-year operating life. In addition to the lenses on the trackers, palletized parquets were stored outside (out of the direct sunlight) at the Solar Village site.

A photograph of the system during its operation is provided in Figure 1(a); see also Ref. [18]. An example M-M module is shown in Figure 1(b). The module in Figure 1(b) was operated on a tracker at the National Renewable Energy Laboratory (NREL) in Golden, Colorado, for 1-2 years, prior to being stored in a warehouse. Dimples in the surface of the lens may be observed in the inset of Figure 1(b), particularly in the reflected image of the overhead fluorescent lights. Similar surface texture was observed on other modules, including on those at Solar Village.

The manufacturer's development of the module technology, including details of the lens design, is described in Refs. [26,27,28,29,30,31,32,33]. Refs. [27,33] in particular provide the manufacturer's comprehensive review of the details and considerations related to the CPV design. Because M-M originally envisioned field cleaning of CPV modules, the modules featured a flat lens, with the facets facing inside the module. The M-M modules feature a PMMA lens, $30.5 \mathrm{~cm}$ x $30.5 \mathrm{~cm}$ x $4.5 \mathrm{~mm}$ in size, that operated at a $36.5 \mathrm{x}$ nominal geometric concentration (often approximated as 40x) for the focused spot. The lens-to-target distance within the module was fixed at $35.9 \mathrm{~cm}$ to improve the uniformity of the focused spot, whereas the designed 
focal distance for the lens was $42.7 \mathrm{~cm}$ [27], i.e., corresponding nominal $f /$ number of 1.4 [27]. The facet angle varied with the radius of the lens in nine discrete increments. The acceptance angle for the lens was $\pm 1.2^{\circ}$, based on $90 \%$ of the maximum short-circuit current [26]. Although the theoretical optical efficiency of the lens is $89.7 \%$ [27], the reported efficiency was $85 \%$ [26,28]. The modules featured a circular silicon $(\mathrm{Si})$ cell $(5.7 \mathrm{~cm}$ in diameter), with a corresponding circular gridline pattern. The lens was designed to have the corner facets bend light more than the center facets to compensate for the shape mismatch between the square lens and the round cell $[26,27]$. This "folded" optical design sought to improve flux uniformity (ideally varying the nominal concentration by as much as $1.6 \mathrm{x}-1.9 \mathrm{x}$ ); consequently, the $\mathrm{fl}$ number varied across the lens (decreasing to 0.8 at the corners of the lens) [27]. Two areas of the lens (containing $0.5 \%$ of the overall area) were slightly rippled and predicted to cause a $0.075 \%$ optical loss. As described further in Refs. $[11,32,33]$, the module body consisted of a plastic housing (not PMMA), attached to a finned aluminum heat sink.

Regarding the manufacturer of the lenses, the literature indicates that Martin-Marietta worked with Swedlow Inc. [27,30] (later purchased by PPG Industries), who frequently manufactured PMMA Fresnel lenses at that time by casting. Project references also noted that compression molding was a popular, applicable manufacturing method at the time of the Solar Village and Sky Harbor installations. Optical Sciences Group Inc. (OSG, later purchased by the 3M Company), a lens tooling and Fresnel lens manufacturer, was acknowledged as the Solar Village lens subcontractor [32]. Specifications for the lens manufacture included a maximum thickness variation of $0.64 \mathrm{~mm}$ and maximum of $1 \mathrm{mrad}$ deviation for the prism curvature [27]. The radius of 2.5 micrometers was sought for the facet tips [27,31].

Regarding the Solar Village site, the most significant reliability issue concerned fatigue failure of the solder die attached to the alumina substrate or in the cell-to-cell interconnects, resulting in an open circuit $[16,19,20,22]$. Other failure modes included: high series resistance (because of the round interconnect wire geometry and cell attachment metallization [31,32]); the tracking electronics (resistor and capacitor failure from water ingress); drive key breakage (because of being untempered, causing mechanical failure of azimuth tracking); component failure (feedback potentiometer) on the tracker electronics board; water-saturated Kapton insulator tape in the module junction boxes; mechanical fatigue of the tracker control cables; soiled tracker sun sensors; soiling of the module; delamination of the carrier/heat-sink interface; and a singularity failure for the 
tracker software at solar noon $[16,17,19,20,23,24,25]$. Regarding the lenses, discoloration (lens entirely yellow) was observed for $\sim 2 \%$ lenses $[23,24]$. This was originally attributed to UV stabilizer, but was later found to come from the lens adhesive. Many of the aforementioned problems were quickly resolved at the installation. For example, the discoloration and delamination of $\sim 8 \%$ of the lenses was fixed using a replacement silicone adhesive

Lenses fielded for 27 or 22 years in Phoenix are also explored in Refs. [9,10]. The oldest lenses were deployed using 80 trackers for $225 \mathrm{~kW}$ in Phoenix for 27 years: 5 years at the Sky Harbor airport starting in 1982, then 22 years at the Arizona Public Service (APS) Solar Test and Research (STaR) center in Tempe. The fabrication and initial history of the installation is described in Refs. [34,35,36,37,38,39]. The veteran modules were washed occasionally using a high-pressure spray (with no physical contact) at Sky Harbor, but were not cleaned at APS

The 27-year veteran modules consisted of the M-M design. Some improvements from the Solar Village site were incorporated into the Sky Harbor system, including the component materials used [31]. The dominant reliability issue identified for the Sky Harbor site was inverter operation [22,38]. Other issues mentioned include: condensation (when modules were not stowed face down overnight); open interconnects (poor solder joints); ground shorts (from degradation of the Kapton insulator); and key breakage (on the tracker drive mechanism). No issues related to the lens were mentioned.

The 22-year veteran modules were manufactured by the Intersol Power Corporation, which formed out of the M-M CPV program. The Intersol design [32,40,41, 42] was a subsequent generation of the M-M design, with a $20.6 \mathrm{~cm} \times 20.6 \mathrm{~cm} \times 3.6 \mathrm{~mm}$ lens that operated at a 70x nominal geometric concentration (originally envisioned at $84 \mathrm{x}$ ) for the focused spot. The lens size was chosen based on an iterative optimization targeting a minimum module cost for a $2.67-\mathrm{cm}$ square $\mathrm{Si}$ cell. The focal distance for the lens was $26.0 \mathrm{~cm}$, i.e., corresponding $f /$ number of 1.26 . The modules featured a $2.3 \mathrm{~cm}$ x $2.3 \mathrm{~cm}$ square $\mathrm{Si}$ cell (presumably some light was lost outside the cell, like the first M-M CPV design, reducing the nominal geometric concentration). The module body consisted of a plastic housing attached to an aluminum heat sink. The Intersol modules in this study were always mounted on a 2-axis tracker at APS-STaR, but were not cleaned. 


\subsection{LITERATURE REVIEW: ANTICIPATED LENS DURABILITY ISSUES}

The durability of formulated PMMA after 22 years of field aging was examined prior to the time of the Solar Village installation [30]. The study compared hemispherical spectral transmittance (obtained with an integrating sphere), direct spectral transmittance (acceptance angle of $\pm 1.5 \mathrm{mrad}$, i.e., $\pm 0.086^{\circ}$ ), and diffuse spectral transmittance (the difference of hemispherical and direct transmittance). That study identified rounding of the cut-on wavelength at $\sim 400 \mathrm{~nm}$ with a stable UV cut-on wavelength at $\sim 390 \mathrm{~nm}$-indicating discoloration of the aged specimen, with retention of the UV absorber. The weathered sample showed a $12 \%-4 \%$ variation in diffuse transmittance with wavelength from $450-900 \mathrm{~nm}$, respectively. At the time of the module development work, M-M anticipated a $1 \%$ loss from UV degradation over 10 years [27].

The artificial weathering of more contemporary PMMA formulations is examined in Ref [43]. These specimens were examined periodically after steady-state artificial aging up to 1,080 cumulative days using a source irradiance of $114 \mathrm{~W} \cdot \mathrm{m}^{-2}$ (for $300 \leq \lambda \leq 400 \mathrm{~nm}$ ), chamber temperature of $60{ }^{\circ} \mathrm{C}$, and chamber relative humidity $(R H)$ of $60 \%$. Some materials discolored (becoming yellow) whereas other materials maintained a neutral color cast with a grey (haze-generating) appearance. The loss of the UV absorber was identified for the discolored materials, based on a shift in the UV cutoff toward shorter wavelengths. A decrease in the molecular weight, particularly for the discolored specimen, with negligible change in the polydispersity (distribution of molecular-weight distribution profiles) was attributed to random chain scission. Differences in the degradation of the two materials in Ref. [43] were attributed to the material formulation. Although not described in Ref. [43], the M-M and Intersol lenses from APS-STaR were also subjected to the same artificial weathering [44].

Damage to the veteran M-M lenses at APS-STaR was examined in Ref. [10], where optical transmittance was compared to molecular weight quantified using liquid chromatography. Material damage was identified from the weight-average molecular weight, which was decreased on the incident surface relative to the value of $107,000 \mathrm{~g} \cdot \mathrm{mol}^{-1}$ for the bulk material. Through-thickness chain scission was attributed to UV radiation. Successive cross-sections of the lens examined indicated that UV degradation was greatest at the incident surface, extending at least $0.5 \mathrm{~mm}$ into the PMMA. Optical transmittance and yellowness index were also to improve as the specimen surface was removed. 


\subsection{LITERATURE REVIEW: CRAZING OF PMMA}

The process of crazing involves the microcracking and accumulation of damage in PMMA. Crazes have been observed for PMMA in creep-rupture tests, with lateral crack widths up $6 \mu \mathrm{m}$ and crack lengths up to 120 $\mu \mathrm{m}$ [45]. These sizes well exceed one-quarter wavelength for visible light, a rule-of-thumb threshold for optical scattering. Crazing of PMMA in response to an applied static load is examined in Refs. $[46,48,49,50,51,52,53,54,55]$. The stress fields and conditions required to initiate and propagate crazes (the process of "normal stress yielding") are examined in Refs. [52,56,57,58,59,60]. Upon fracture, PMMA will form a colorful 700-nm-thick surface layer consisting of crazed, oriented material [49,50]. Crazes may form in PMMA, e.g., at the surface, in response to sufficient mechanical strain [41,48]. A bending stress greater than 14 MPa is identified in Ref. [30] as the threshold for preventing crazing during manufacturing. A rate dependence was observed, particularly for an applied mechanical load [53,55], where the morphology and amount of damage varied with the load rate [55]. Craze behavior is examined for applied dynamic loads in Refs. $[46,55,61,62,63,64,65]$. The crazing associated with mechanical fatigue is examined in Refs. $[46,63,64,65]$. Craze formation under static conditions $\left(<10^{-1} \mathrm{~Hz},[46]\right)$ depends solely on the stress/strain behavior of PMMA [65], whereas craze formation during dynamic conditions varies with the applied load (e.g., regimes bounded by the applied stress-intensity thresholds of $0.35,0.6$, or $\left.1 \mathrm{MPa} \cdot \mathrm{m}^{0.5},[64]\right)$, the material's viscoelastic response, and the interaction between the craze and bulk material.

Much of the study of craze formation and the interaction of crazes with the environment comes from the field of fracture mechanics $[47,48,50,51]$, i.e., which examines the formation of crazes and their coalescence, facilitating the propagation of an advancing crack. Some findings from the literature can, however, be applied to CPV lens application. A greater density of short crazes was formed in relatively dry or mildly water-saturated PMMA, whereas fewer longer crazes were formed in wet PMMA [41,76]. This suggests that desert locations may more immediately facilitate surface crazing. The stress required to induce crazing (or rupture) was seen to decrease with time for samples weathered in air [84]. This may follow from the UV degradation of PMMA [2], where the molecular weight (therefore, the critical fracture toughness, $K_{\mathrm{IC}}$ ) was reduced by random chain scission-which would be expected to make the material more prone to environmental stress cracking (ESC, including surface craze formation) [85]. Because it cannot craze during plastic deformation, the molecular 
weight of $10,000 \mathrm{~g} \cdot \mathrm{mol}^{-1}$ is identified as a critical threshold for PMMA, below which it becomes extremely brittle [2]. Surface roughness was found to reduce the critical strain required for craze formation [53]. There may then be an interaction with abrasion damage, e.g., airborne sand or abrasion from cleaning.

\subsection{LITERATURE REVIEW: ENVIRONMENTAL STRESS CRACKING OF PMMA}

Many amorphous polymers, like PMMA, are affected by ESC, where the mechanical behavior including craze formation can be affected by a solvent. The solvent may be a liquid or gas, e.g., the thermal activation for the enabling process of crazing in $\mathrm{N}_{2}, \mathrm{Ar}, \mathrm{O}_{2}, \mathrm{CO}_{2}$, and water vapor are quantified in Ref. [66]. Studies examining ESC in conjunction with an applied static load include Refs. $[41,53,58,59,60,66,67,68,69,70,72,73,74,75,76,77,78]$, whereas fatigue is examined in Refs. $[61,62,63,64,65]$. The effect of water, where polar PMMA can absorb up to $2.2 \%$ wt. [73], is examined in Refs. $[41,60,67,68,69,70,71,72,73,74,75,76,77,78,79,80,81,82]$. Hygroscopic methanol, where the concentration of water stabilizes at $1.07 \%$ in a standard laboratory environment [66], is also often examined [46,53,66,74,77]. Some $40 \%$ to $60 \%$ of the absorption of solvent into PMMA will occur within microvoids in the material [86], while the remaining absorption will cause the material to swell, causing a compressive strain that may reduce the likelihood of crazing at the surface [77]. Because solvents reduce yield strength, they also affect the propagation of a crack tip, i.e., the process of craze and fibril generation as well as the blunting of the crack tip [77]. $K_{\mathrm{IC}}$ was observed to vary from $0.7 \mathrm{MPa} \cdot \mathrm{m}^{0.5}$ to $0.95 \mathrm{MPa} \cdot \mathrm{m}^{0.5}$ with water concentration, where the threshold of $0.8 \%$ wt. water [41] (75\% relative humidity in a laboratory environment [41]) distinguished between the fracture propagation modes as well as the corresponding fractography [78]. Following from the toughness, the work of fracture is increased four-fold for wet PMMA [66]. The length of the craze ahead of the crack tip increases with water content, enhancing the size of the plastic zone and the corresponding toughness [75]. Although $K_{\text {IC }}$ is increased, the fracture strength instead decreased $[66,69,72,73,74,77]$ because the craze became wider [71] and longer [75], whereas the connecting fibrils at the crack became plasticized, resulting in a shorter fibril lifetime [75]. The maximum strain to failure was identified for the water concentration of $1.1 \%$ wt., above which elongation was reduced by clustering of water within PMMA [72]. To explain, a population of crazes will form ahead of the crack, which advances through advantageous coalescence in relatively dry or mildly water-saturated PMMA, whereas crack advancement occurs at a continuous rate along a single craze in 
wet PMMA [78]. The displacement rate of $10^{-1} \mathrm{~Hz}$ was identified as the threshold between elastic and combined viscoelastic response (where craze formation is subject to plasticization) [46]. At high load rates, PMMA responds like dry material because water does not have time to diffuse to the craze tip or plasticize the adjacent fibrils [77,82]. A time-temperature-stress superposition was applied in a Williams-Landel-Ferry representation to estimate the crazing damage in creep-rupture experiments $[69,83]$.

Although many of the effects of ESC are modest, the following considerations or indicators should be mentioned: The mechanical modulus of PMMA is typically decreased on the order of 5\% with water concentration $[72,73,75]$. The static fracture strength of PMMA, however, can be decreased by as much as $40 \%$ because ESC affects crazing [66,69,77]. The effects of moisture should be considered when designing a lens to withstand hail or wind loads. The fatigue life of PMMA decreases by two orders of magnitude with water content up to $1 \%$ wt. [81]. CPV lenses are not, however, typically load-bearing components, which should reduce their internal stress and corresponding propensity to fatigue. The glass transition temperature $\left(T_{\mathrm{g}}\right)$ may be decreased by as much as $25^{\circ} \mathrm{C}$ for PMMA by water $[70,73,75]$, which could affect its dimensional stability through the process of physical aging. The decrease in $T_{\mathrm{g}}$ aids the propensity for wet PMMA to craze [66]. Given the $T_{\mathrm{g}}$ of $105^{\circ} \mathrm{C}$ for a dry PMMA formulation, the corresponding reduced $T_{\mathrm{g}}$ of $80{ }^{\circ} \mathrm{C}$ is sufficiently high such that physical aging would not be expected for lens operating temperatures less than $60^{\circ} \mathrm{C}$, i.e., $T_{\mathrm{g}}-20^{\circ} \mathrm{C}$ [87].

\subsection{GOALS OF THE STUDY}

Veteran lenses from the Solar Village in Riyadh and Sky Harbor/APS-STaR sites in Phoenix were compared with reference lenses (stored in the field or separately in a warehouse). The goal of the study was to quantify performance of the veteran lenses and identify the dominant degradation modes. Characteristics examined include: optical transmittance, including both lens and material measurements; lens focal distance; lens curvature; optical scattering; physical geometry, including the material integrity at the incident surface and the lens facets; surface morphology, including scanning electron microscope and atomic force microscopy measurements; and molecular weight, via gel permeation chromatography. The results are presented here to assess the feasibility of the use of PMMA in lenses for CPV modules as well as to provide feedback toward developing reliable primary optics used for CPV. 


\section{EXPERIMENTAL}

\subsection{SPECIMENS}

Lens specimens obtained from the Solar Village site include veteran lens series ("KACST-O," used for CPV for 20 years); and reference lens series ("KACST-R," obtained from the stack of palletized parquets). The KACST-R samples were exposed to a similar ambient thermal environment as the KACST-O lenses, but were shielded from UV by the stack. Additional reference lenses were obtained from NREL ("NREL-W"); these had been fielded for 1-2 years in Golden for module performance measurements and then stored in a wooden crate in a warehouse. These lenses were physically cleaned during field use, e.g., wet scrubbed with a damp lens tissue. Lens specimens obtained from APS include veteran lenses (“APS-O,” from M-M modules fielded for 27 years) and additional veteran lenses ("APS-I," from Intersol modules fielded for 22 years). No reference Intersol lenses (lacking full field exposure) were available. The nominal thickness of the M-M lenses (KACST-O, KACST-R, NREL-W, and APS-O) was $4.51 \mathrm{~mm}$, whereas the nominal thickness of the Intersol lenses (APS-I) was $3.61 \mathrm{~mm}$.

\subsection{LENS PERFORMANCE, FOCAL DISTANCE, AND CURVATURE MEASUREMENTS}

Indoor measurements of lens performance were carried out using the Helios 3198 Solar Simulator, represented in Figure 2, developed by the Instituto de Energía Solar - Universidad Politécnica de Madrid (IESUPM) $[88,89,90]$. The Solar Simulator uses a xenon flash lamp and a 2-meter-diameter collimator mirror to produce a light distribution at the input aperture of the lens that is similar to the sun-not only in angular size and distribution ( $90 \%$ of the total irradiance is contained within a solid half-angle of $0.4^{\circ}$ ), but also, the equivalent to the AM1.5D spectrum [92]. To examine the effect of focal distance, the test cell can be moved relative to the lens, with a minimum increment for the stepper motor of less than $5 \mu \mathrm{m}$. To verify the colorcast present during measurement, the Solar Simulator contains a spectroheliometer consisting of separate isotype cells (GaInP, GaInAs, and Ge), calibrated against the AM1.5D spectrum. The optical efficiency ( $\eta$, \%) of a lens measured in the Solar Simulator is calculated as the ratio of power at the input and output of the concentrator [93]:

$$
\eta=100 \cdot \frac{\mathrm{E}_{\mathrm{e}, \text { out }} \cdot \mathrm{A}_{\text {cell }}}{\mathrm{E}_{\mathrm{e}, \text { in }} \cdot \mathrm{A}_{\text {lens }}}
$$


The input irradiance $\left(E_{\mathrm{e}, \mathrm{in}}, \mathrm{W} \cdot \mathrm{m}^{-2}\right)$ at the entrance of the lens area $\left(A_{\text {lens }}, \mathrm{m}^{2}\right)$ and the output irradiance $\left(E_{\mathrm{e}, \text { out }}, \mathrm{W} \cdot \mathrm{m}^{-2}\right)$ at the focus of the lens $\left(A_{\text {cell }}, 14.44 \mathrm{~cm}^{2}\right)$ are measured using two different irradiance sensors of the same technology (e.g., two silicon solar cells) calibrated at 1 sun for the AM1.5 terrestrial direct solar spectrum. $E_{\mathrm{e}, \text { out }}$ is known to vary as a function of the electrical current from the test sensors, Equation 2. Each lens was first aligned with the cell at a focal distance of $400 \mathrm{~mm}$. A series of scans was then performed where the separation distance between the lens and the cell was varied to quantify the effect of focal distance. Indoor measurements were carried out for the entire lens $(30.5 \mathrm{~cm} \times 30.5 \mathrm{~cm})$ as well as the 8 -cm central portion of each lens, measured using a square mask. The masked measurements were performed using the Si cell (effective spectral bandwidth of 300-1,150 nm), the cell filtered with a hot mirror (390-750 nm), and the cell with a cold mirror $(675-1,150 \mathrm{~nm})$.

$$
\mathrm{E}_{\text {out }}\left(\mathrm{W} \cdot \mathrm{m}^{-2}\right)=\frac{\mathrm{I}_{\text {cell at equivalentAM1.5D }}(\mathrm{A})}{\mathrm{I}_{\text {cell at 1 sun,AM1.5D }}(\mathrm{A})} \cdot 1000 \mathrm{~W} \cdot \mathrm{m}^{-2}
$$

In addition to the overall performance and spectral performance, the curvature of the lenses was characterized using a recently developed method [91]. The mean curvature $\left(\kappa_{\mathrm{m}}, \mathrm{m}^{-1}\right)$ was measured from the Fresnel reflection off the front surface of each lens. $\kappa_{\mathrm{m}}$ is defined as the inverse of the mean radius of curvature $\left(R_{\mathrm{m}}, \mathrm{m}\right)$. The direction (concave or convex) and magnitude of curvature were quantified from an optical image (Retiga ExiFast CCD camera, QImaging Co.) of the distortion of a checkerboard reference pattern. Curvature estimations are performed with a resolution on the order of $1 \mathrm{~cm}^{-1}$, depending on the area of the lens under evaluation and the pixel resolution of the CCD detector. The spatial sampling resolution of the curvature depends directly on the dimensions of the periodic pattern used (e.g., $2.5 \mathrm{~cm}$ x $2.5 \mathrm{~cm}$ grid in the measurements here).

\subsection{LENS MATERIAL TRANSMITTANCE AND OPTICAL SCATTERING MEASUREMENTS}

Optical measurements were performed using a Cary 5000 dual-beam ultraviolet-visible-near infrared (UV-VIS-NIR) spectrophotometer (Agilent Technologies Inc.) with an integrating sphere and a Cary 500 dualbeam UV-VIS-NIR spectrophotometer with no integrating sphere. Transmittance was measured similar to Ref. [94] from 200-2,650 nm with a 1-nm interval for the Cary 5000 and from 200-3300 nm with a 1-nm interval for the Cary 500. As in Refs. $[95,96]$, spectra were obtained and then analyzed relative to the AM1.5D spectrum 
[92] to quantify the solar-weighted transmittance of photon irradiance $\left(\tau_{\mathrm{sw}}\right)$, yellowness index $(Y I)$, and the UV cut-off wavelength $\left(\lambda_{\mathrm{cUV}}\right)$. Haze was computed from the hemispherical transmittance $\left(\tau_{\mathrm{h}}\right.$, Cary 5000$)$ and direct transmittance $\left(\tau_{\mathrm{d}}\right.$, Cary 500) spectra as: haze $=\left(\tau_{\mathrm{h}}-\tau_{\mathrm{d}}\right) \cdot \tau_{\mathrm{h}}{ }^{-1}$.

Sets of $6.7 \mathrm{~cm} \times 4.4 \mathrm{~cm}$ coupon specimens were cut from the center of veteran lenses for the transmittance measurements. Measurements were first performed using the Cary 5000 after cleaning the lenses with a deionized water spray to remove contamination. To study the optical effects from the lens surfaces, the facets were milled from the back surface using a steel high-speed cutting tool (P/N 01881960, Interstate Tool Corp.); the samples were then polished using the series of 30-, 15-, 9-, 3-, 2-, and 1- $\mu \mathrm{m}$ flexible polishing papers (Zona series, 3M Company). Optical measurements were then performed using the Cary 5000 and Cary 500. The incident surface was then polished using the same series of papers, followed by measurements using the Cary 5000 and Cary 500. An index-matched silicone oil (Fluid AP 100, Wacker Chem. Corp.) was used during the optical measurements of the polished surface(s) to fill in surface roughness and scratches. An analysis procedure for the data (described in Ref. [3]) allows the optical attenuation coefficient to be evaluated so that the thickness-compensated transmittance may be determined for the original thickness as opposed to the measured thickness after milling and polishing.

The direct transmittance was further characterized for additional coupon specimens (milled and polished to remove the facets from the back surface as above, but with no index-matched silicone oil applied) using the Very Low Angular Beam Spread (VLABS) instrument at Fraunhofer ISE [97]. VLABS quantifies the angleresolved scattering function by comparing the images of a monochromatic beam of light on a CCD sensor, before and after a sample is inserted. The diffused light of a 631-nm light-emitting diode (LED) source is collimated ( 1 mrad half divergence angle) and forms a beam with diameter (i.e., spot size on specimen) of about $7 \mathrm{~mm}$. The half field of view for VLABS extends up to $30 \mathrm{mrad}\left(1.72^{\circ}\right)$. The instrument has an absolute accuracy of $0.5 \%$ for transmittance, with an angular resolution of $0.05 \mathrm{mrad}\left(0.0029^{\circ}\right)$. The ideal optical transmittance for bulk PMMA can be estimated from Equation 3, where $\tau_{\text {theo }}$ represents the theoretical transmittance, \%; and $n$ refers to the refractive index.

$$
\tau_{\text {theo }}=100 \cdot\left(1-\left(\frac{1-n}{1+n}\right)^{2}\right)^{2} \cdot\left(1-\left(\frac{1-n}{1+n}\right)^{4}\right)^{-1}
$$


The value of $n=1.490$ for an unaged PMMA (PMMA 8N, Evonik Industries AG) was confirmed against the literature [98] using an Abbe 60/ED refractometer (Bellingham + Stanley Ltd.) on a $2.17 \pm 0.06 \mathrm{~mm}$ thick commercially PMMA sheet specimen (containing proprietary formulation additives), which implies a $\tau_{\text {theo }}$ of $92.5 \%$ at $631 \mathrm{~nm}$. Equation 4 considers only the surface reflectance for a bulk material, but does not account for material-specific absorptance. Absorptance is neglected here because it is assumed to have an effect that is less than the measurement uncertainty.

\subsection{MEASURMENT OF PHYSICAL CHARACTERISTICS}

A Dimension 3100 (Veeco Instruments Inc.) atomic force microscope (AFM) was used to perform surface topography scans in tapping mode. The radius of curvature of the silicon AC160TS (Asylum Research Corp.) tips used was nominally $7 \mathrm{~nm}$, with an included tip cone angle of $40^{\circ}$. After spraying with deionized water to remove particulate contamination, the top surfaces of coupon specimens were measured using $90 \times 90$ $\mu^{2}$ then $20 \mathrm{x} 20 \mu \mathrm{m}^{2}$ scans with 512 pixels in each direction (i.e., $\sim 180 \mathrm{~nm}$ or $\sim 40 \mathrm{~nm}$ lateral resolution), which were then processed using the flatten and low-pass filter $(3 \times 3$ pixel averaging) software features. The surface roughness (of the measured area) and the size of characteristic features (within a line scan) were determined using the instrument's software. Electron microscopy was also performed using a field-emitting scanning electron microscope (Quanta 600, FEI Co.). AFM measurements were performed on specimens in addition to the front surface of the lenses, including: one of the reference lenses from the Solar Village site, on the faceted surface after it was milled and polished; and a stock PMMA sheet material (also containing proprietary formulation additives, but different from the commercial PMMA specimen above), after the protective kraft paper was removed from the surface. The microscopy measurements were performed on at least three locations on each specimen examined.

The material integrity, including porosity at the first surface as well as the tip- and valley-lens radius of the lens facets, was examined on cross-sectioned coupon specimens. Specimens were cut to size $(2 \mathrm{~cm} \times 2 \mathrm{~cm})$ using a hand saw and then potted in a two-part addition cure epoxy (P/N 145-10015, Allied High Tech Products, Inc.). After curing for 24 hours at ambient temperature, the samples were cut across the direction of the lens facets using a hand saw, then polished using a Multiprep Polisher (P/N 10-1000, Allied High Tech Products, Inc.) using a series of plain black-diamond lapping films (30-, 15-, 9-, 6-, 3-, 1-, 0.5-, and 0.25- $\mu \mathrm{m}$ grit, P/N 50- 
300XX series, Allied High Tech Products, Inc.). The specimens were rinsed with deionized water, dried with pressurized air, and then desiccated before imaging. Optical images were obtained on an AxioImager.M2m microscope (Carl Zeiss AG) equipped with an AxioCam MRc5 camera (Carl Zeiss AG). Image contrast was improved for measurements using differential interference contrast (DIC, "Nomarski") microscopy. Scanning electron microscopy (SEM) was performed using the Quanta 600. A large working distance ( 20 mm) and low acceleration voltage $(2 \mathrm{kV})$ were used to limit charge accumulation on the specimens during electron imaging. Estimates of the tip and valley radius for the lens facets were obtained relative to circles drawn in the imaging software. Three optical and three electron images were obtained for each specimen type at both the incident and faceted surfaces of the lenses.

\subsection{MEASURMENT OF POLYMER CHARACTERISTICS}

Gel permeation chromatography (GPC) analysis was performed using a high-performance liquid chromatograph (HP1050, Agilent Technologies Inc.) attached to a refractive-index detector. The outer $100 \mu \mathrm{m}$ of the first surface of coupons specimens $(1 \mathrm{~cm} \mathrm{x} 1 \mathrm{~cm})$ was tomed in $0.5-\mu \mathrm{m}$ increments using an 820 microtome (American Optical Corp.). The shavings were dissolved in tetrahydrofuran (THF, J.T. Baker Chemical Co., HPLC grade) at $1-2 \mathrm{mg} / \mathrm{mL}$ and then filtered $(0.45-\mu \mathrm{m}$ nylon membrane syringe filters) before analysis. The sample injection volume was $200 \mu$ L. Four GPC columns (PL1110-6120, PL1110-6130, PL11106140, and PL1110-6150, Polymer Laboratories Ltd., 300 x $7.5 \mathrm{~mm}$ ) packed with polystyrene-divinyl benzene copolymer gel beads (10- $\mu \mathrm{m}$ diameter) having nominal pore diameters of $10^{4}, 10^{3}, 10^{2}$, and $10^{1} \mathrm{~nm}$ were used, connected in series in order of decreasing pore diameter. THF was used as the eluant at the flow rate of 1.0 $\mathrm{mL} \cdot \mathrm{min}^{-1}$. The measured retention time was converted into molecular weight by applying a calibration curve established using ten PMMA standards (Agilent Technologies Inc.) of known molecular weight (from $1.3 \times 10^{6}$ to $3 \times 10^{3} \mathrm{~g} \cdot \mathrm{mol}^{-1}$ ). The molecular-weight distribution parameters were calculated using Cirrus GPC software (Polymer Laboratories Ltd.) from the equations:

$$
\begin{aligned}
& \overline{M_{n}}=\frac{\sum N_{i} M_{i}}{\sum N_{i}} \\
& \overline{M_{w}}=\frac{\sum N_{i} M_{i}^{2}}{\sum N_{i} M_{i}}
\end{aligned}
$$




$$
P D=\frac{\overline{M_{w}}}{\overline{M_{n}}}
$$

In the analysis, $\overline{M_{p}}$ represents the peak molecular weight, i.e., the molecular weight of the highest peak in each data profile; $\overline{M_{n}}$ is the number-average molecular weight $\left\{\mathrm{g} \cdot \mathrm{mol}^{-1}\right\} ; N_{\mathrm{i}}$ is the number of molecules $\{$ molecules $\} ; M_{\mathrm{i}}$ is the molecular weight $\left\{\mathrm{g} \cdot \mathrm{mol}^{-1}\right\} ; \overline{M_{w}}$ is the weight-average molecular weight $\left\{\mathrm{g} \cdot \mathrm{mol}^{-1}\right\}$; and $P D$ is the polydispersity $\{$ unitless $\}$. Measurements were performed using the primary refractive-index signal for PMMA, not the lesser signals attributed to copolymers and additives.

\subsection{ADDITIONAL CHARACTERIZATIONS}

Additional characterizations performed, but not described in detail here, include: scans of optical reflectance spectra; scans of the active electronic structure, via UV-VIS fluorescence spectroscopy; and identification of low-molecular-weight components of the lenses, including the formulation additives using gas chromatography-mass spectroscopy (GC-MS) [44]. Key details of those measurements include: 1) Similar to the transmittance measurements, reflectance was measured on coupon-lens and polished-lens specimens using the Cary 5000 and Cary 500; 2) As in Ref. [99], UV-VIS fluorescence spectroscopy was performed with a FL112XI Fluorolog-II (SPEX Industries Inc), which uses a Xe-arc lamp source (450-W bulb), Hamamatsu R928 photomultiplier (PMT) emission detector, and Hamamatsu R508 PMT reference detector (using Rhodamine B as the quantum counter); 3) Samples for GC-MS were prepared using a dissolution mixture of $75 \mathrm{wt} \%$ dichloromethane (DCM, $\mathrm{CH}_{2} \mathrm{C}_{12}$ ): $12.5 \mathrm{wt} \%$ petroleum ether: $12.5 \mathrm{wt} \%$ diethyl ether (ether, $\mathrm{C}_{2} \mathrm{H}_{5} \mathrm{OC}_{2} \mathrm{H}_{5}$ ). Three grams of PMMA (broken to $<1-\mathrm{cm}^{2}$ pieces) could be dissolved in 8 grams of solvent mixture overnight, with the aid of agitation. Precipitation of the polymer was then performed by combining 1 volume of sample solution with 3 volumes of $50 \mathrm{wt} \%$ ether - $50 \mathrm{wt} \%$ petroleum ether. Precipitated solutions were decanted and injected into the GC for analysis. Analysis was performed using a 2-dimensional high-resolution Pegasus GCxGC-TOFMS time-of-flight mass spectrometer system (LECO Corp.).

\section{RESULTS}

\subsection{LENS PERFORMANCE EMASUREMENTS}

The results of the lens characterization using the IES-UPM Solar Simulator are shown in Figure 3 and Figure 4. The results are shown in Figure 3 for the veteran lens (KACST-O-6, 20y use on a tracker) and 
reference lens (KACST-R-06, from a pallet stored outdoors) from the Solar Village site, which are also compared to the veteran M-M lens (APS-O-06, 27y use on tracker) fielded in Phoenix and a reference lens (NREL-W-06, stored in a warehouse) from NREL. The results have been scaled relative to the maximum for specimen KACST-R-06, with error bars indicated for 2 standard deviations (S.D.). Results from each specimen are shown for measurements obtained from the entire lens or the central (masked) portion. A quadratic or linear best fit has been applied to the discrete measurements to group the data and guide the eye. A significant variation occurs with the focal distance for the measurements made using the entire lenses. The optimum focal distance for the measurements of the entire lenses is indicated at the top of the figure with a hash mark. As quantified in Table 1, the rank of the focal distance follows from greatest to least as: APS-O-06 > NREL-W-06 $>$ KACST-O-06 > KACST-R-06. The variation in optical efficiency $\left(\eta_{\mathrm{o}}\right)$ with focal distance is greatly reduced for the masked measurements. For both the unmasked and masked measurements, a reduced efficiency is observed for both veteran lenses, relative to both reference lenses. The $\eta_{\mathrm{o}}$ of $92 \%$ for the masked measurement is observed for the veteran lens KACST-O-06 relative to the reference lens KACST-R-06. The rank of the masked $\eta_{\mathrm{o}}$ measurements follows from greatest to least as: KACST-R-06 > NREL-W-06 > KACST-O-06 > APS-O-06.

The results are shown in Figure 4 for the center of the same lenses, measured using either a hot mirror (favoring visible wavelengths) or a cold mirror (including both VIS and NIR wavelengths). As in Figure 3, the performance of both reference lenses exceeds that of both veteran lenses. The $\eta_{\mathrm{o}}$ of the veteran lenses is decreased at short wavelengths, particularly for APS-O-06, which approaches a $10 \%$ loss in transmittance compared to KACST-O-06. The $\eta_{0}$ of the warehouse (NREL-W-06) reference lens is less than that of the palletized reference lens (KACST-R-06) at short wavelengths (hot mirror), with more similar $\eta_{\mathrm{o}}$ at longer wavelengths (cold mirror).

Table 1 summarizes results of the solar simulator characterization, with some values compared relative to the spectrophotometer measurements of coupon specimens with the faceted surface milled and then polished. The absolute $\eta_{\mathrm{o}}$ is given for the entire (unmasked) lens, which is compared at the focal distance of $39.7 \mathrm{~cm}$. At that focal distance, the flattest lens (NREL-W-06) is the most efficient, whereas the veteran lenses are at least $10 \%$ less efficient. $\eta_{\mathrm{o}}$ is then compared (relative to KACST-R-06) for the entire lenses, then for the central 
portion of the lenses (including nominal, cold-mirrored, and hot-mirrored measurements), then for the coupon specimens (analyzed for the corresponding spectral bandwidth of the Si detector, cold-mirrored, and hotmirrored measurements). The reference lenses typically have comparable $( \pm \leq 2 \%) \Delta \eta_{\mathrm{o}}$ values. As in Figure 4 , $\Delta \eta_{\mathrm{o}}$ is greatest for APS-O-06, particularly at shorter wavelengths. $\Delta \eta_{\mathrm{o}}$ is greatest for the KACST-O-06 specimen, when measured using the Solar Simulator (where the specimens all contain lens facets). The optimum focal distance as well as the mean curvature value for the entire lens measurements in Figure 3 is also given in Table 1. A range of focal distances is observed in Table 1 relative to the $\mathrm{M}-\mathrm{M}$ design value of $42.672 \mathrm{~cm}$. The deformed shape was measured to be concave for the KACST-R-06 and KACST-O-06 lenses, convex for the lens fielded in Phoenix (APS-0-06) and flat for the lens stored in the NREL warehouse (NREL-W-06). The rank for $R_{\mathrm{m}}$ for the lenses in Table 1 follows from greatest to least in the same order as the rank for $f$ in Table 1 and Figure 3, i.e., APS-O-06 > NREL-W-06 > KACST-O-06 > KACST-R-06.

For the measurements examining the entire lenses, differences on the efficiency data follow from the lenses' design, deformed shape, and optical transmittance. Regarding the design, the M-M lens features cornerlocated facets adjusted to redistribute the light from a square lens onto a circular cell $[26,27]$. Because the lenses have the same folded design, however, the lens design cannot account for all the observed difference between the unmasked and masked measurements in Figure 3. Regarding the deformed shape, its effect (observed for the entire lens data profiles in Figure 3) is directly related to light leakage that varies with the focal distance: light is spilled outside of the area of the Si detector cell. Lenses with concave (negative curvatures) and convex (positive curvatures) shapes have their maximum of optical efficiency at shorter and larger focal distances, respectively, relative to the lens with a flat shape (NREL-W-06). The rank order in Table 1 was consistent between $f$ and $R_{\mathrm{m}}$, suggesting that the curved shape of the lens is capable of affecting incident light. In this study, the results for the measurement of the entire lens are suspected to be limited by the lens curvature (in addition to the folded design), which affects the size of the focused spot at the detector. For the flat Fresnel lens, the optimum focal distance $(39.7 \mathrm{~cm})$ is less than the designed focal distance $(42.7 \mathrm{~cm})$ most likely because the diameter of the detector cell $(5.7 \mathrm{~cm})$ is smaller than the projected spot size (diameter of $8.8 \mathrm{~cm})$. Although not examined further here, some variation in the focal distance may follow from the lens curvature. The reduction in efficiency due to the deformed shape of the lenses - including the disparity between the optimum focal distance 
and the intended focal distance-is under-represented in the measurements in Figure 3. The effect of the shape is reduced because each lens is aligned with the receiver (solar cell) prior to the optical efficiency measurement. The same lenses installed in a module could further decrease the module efficiency, because they would not individually be aligned with the receiver during module manufacturing. Remaining differences between the lenses are attributed to their optical transmittance, described below.

For the measurements of the center of the lenses (reducing the effects of the lens design), the focused light is measured with no light lost outside of the cell (reducing the effects of lens curvature). This corresponds to the flatter, parallel data profiles for the masked lenses in Figure 3, relative to the data obtained from the entire lens. The remaining differences between the masked lenses follow from factors in addition to curvature, e.g., material transmittance, surface roughness, or lens facet geometry. A series of additional optical and material characterizations was performed next (summarized in the figures and tables below), because a reduction in lens efficiency remained between the masked lenses.

Because the spectrophotometer measurements were obtained on specimen with the facets removed, the absolute values of the lens and spectrophotometer measurements can only truly be compared for trends rather than for absolute values. In Table 1, however, the difference in $\Delta \eta_{\mathrm{o}}$ measurements for the KACST-O-06 lens between the Solar Simulator and spectrophotometer approaches the 7\% difference between hemispherical and direct transmittance spectrophotometer measurements of the outdoor-weathered PMMA sheet in Ref. [30], suggesting that the loss largely follows from angle-related effects, e.g., optical scattering and/or the lens facets. However, an $\sim 3 \% \Delta \eta_{\mathrm{o}}$ remains between the KACST-O-06 and KACST-R-06 polished coupons, identifying that the incident surface has been degraded by field use. The veteran APS-O-06 lens instead shows a substantial $\Delta \eta_{\mathrm{o}}$ for both the Solar Simulator and spectrophotometer measurements, suggesting loss in performance occurring on the incident surface of the lens. The maximum efficiency of the entire KACST-R-06 reference lens is lower than the maximum efficiency of the entire NREL-W-06 warehouse lens, contrary to the values given by the characterization of the central part of the lenses. This might be explained if even at the optimum focal distance of the entire reference lens (where the spot size is minimized), some light still falls outside of the Si detector because of its greater curvature. 


\subsection{LENS COUPON PERFORMANCE EMASUREMENTS}

The spectral transmittance and haze results obtained using the spectrophotometers are shown for coupon specimens KACST-O-01, APS-O-01, and KACST-R-01 in Figure 5, Figure 6, and Figure 7, respectively. The figures are shown with the ranges on their axes so that they may be readily compared. Transmittance was determined successively for the coupons after they were cut from a lens (labelled "lens" in the figures), then with the Fresnel facets removed ("bmp"), then finally after polishing the front surface ("bmp,fp"). The final, front-polished version of the coupons was always the most optically transmitting. Haze was computed only for the processed coupons ("bmp" and "bmp,fp"). In the figures, an $\sim 1 \%$ offset in $\tau_{\mathrm{h}}$ is observed for the coupon measurements with the facets present relative to the measurements with the facets milled and back surface polished. The greatest loss in transmittance relative to the reference specimens was observed for the APS-O-01 specimen, below $800 \mathrm{~nm}$ in Figure 6. The specimens also all demonstrate a rounded cut-on transition (where they become optically transmitting above $400 \mathrm{~nm}$ ). The corresponding maximum $Y I$ of 3.3 was observed for the APS-O-01 specimen. Regarding their visual appearance, the specimens all had a neutral colorcast. The UV cutoff wavelength $\left(\lambda_{\mathrm{cUV}}\right)$ varied from $372-379 \mathrm{~nm}$ between the test and reference lenses. Haze generally increased for shorter wavelengths for all specimens. Haze was reduced for the veteran specimens when the front surface was polished (-bmp, fp). A significant haze remained for the APS-O-01 specimen, however, even after the front surface was polished. Haze was instead increased for the reference specimens, after the front surface was polished.

Many of the differences between the data profiles in Figure 5, Figure 6, and Figure 7 follow from the progression of the specimen preparation. The transmittance improved consistently upon the removal of the lens facets and polishing of the back surface. The $\sim 1 \%$ difference likely reflects the limitations of the integrating sphere in obtaining $\tau_{\mathrm{h}}$ measurements from specimens containing lens facets, including different incidence angles into the sphere as well as back reflection off of the facets. The subsequent polishing of the front surface was typically found to marginally increase $\tau_{\mathrm{h}}$, more obviously reducing haze for the veteran specimens. Haze is typically seen to increase at shorter wavelengths because of scattering effects, e.g., from surface roughness or contamination remaining from natural soiling. The increase in haze after polishing the front surface of the reference specimens may suggest that the manual polishing renders a nanoscale surface roughness that exceeds 
the roughness of the fabricated lens surface. At the end of the experiment, the APS-O-01 coupon remained the most severely affected, suggesting that it may be damaged into the bulk of the material.

Regarding the rounding of the cut-on transition, this seems to follow from optical scattering rather than discoloration of the PMMA. This conclusion follows from the neutral colorcast, as well as the minimal change in $Y I$ for the veteran specimens. Furthermore, the $\lambda_{\text {cUV }}$ was not greatly different between the specimens, suggesting that the UV stabilization package remains intact within the veteran lenses. A rounding of the cut-on spectrum with a minimal change in $\lambda_{\mathrm{cUV}}$ was anticipated at the time of the development of the M-M CPV technology [30]. In Ref. [30], the initial sharp cut-on transition was observed to round over $\sim 100 \mathrm{~nm}$ on a 22 year-old specimen. A similar range of $\sim 150 \mathrm{~nm}$ is observed for the cut-on transition of the veteran and reference lenses in this study.

The direct transmittance is characterized as a function of the detector's acceptance angle (i.e., half field of view, HFOV) in Figure 8 for the VLABS instrument. The transmittance is generally reduced (on the order of $\sim 3 \%$ ) as the detector's acceptance angle is reduced. The veteran specimens fielded in Phoenix (including Martin-Marietta and Intersol lenses) have a transmittance that is reduced substantially relative to the other specimens. The theoretical transmittance is included in Figure 8, based on the refractive index of PMMA. This data curve lies in close proximity to the unaged, unpatterned (reference) commercial PMMA specimen. A 3\% difference is observed between the reference commercial PMMA specimen and the KACST-R-07 reference specimen at the HFOV of $\pm 30 \mathrm{mrad}$. A $9 \%$ difference is observed between the KACST-R-07 reference specimen and APS-O-07 specimen at the same HFOV. Relative to the range of angles in Figure 8, the Cary 5000 spectrophotometer is believed to have a HFOV on the order of $\pm 2^{\circ}-3^{\circ}$, the M-M CPV design $\pm 1.2^{\circ}$, and contemporary CPV designs on the order of $\pm 0.8^{\circ}-1^{\circ}$.

At the time of the development of the M-M CPV technology, a reduction in transmittance as a function of the detector's acceptance angle was observed in the literature for a specimen naturally weathered for 22 years [30]. A decrease in $\tau_{\mathrm{d}}$ on the order of $1 \%$ was observed as the detector's acceptance angle was varied from 1 to $15 \mathrm{mrad}$. An inflection in the data profile at $2 \mathrm{mrad}$ was also observed in Ref. [30]. The literature results are therefore consistent with those of the reference specimens and coupon KACST-O-07. The rank order for the VLABS measurements is also consistent with the spectrophotometer characterizations. The substantial reduction 
in $\tau_{\mathrm{d}}$ in Figure 8 for APS-O-07 and APS-I-07 specifically identifies optical loss due to scattering. The scattering in Figure 8, with the spectral distribution in Figure 6, is consistent with the reduced $\eta_{\mathrm{o}}$ for the HM measurements of the APS-O-06 specimen in Figure 4.

Regarding the difference between the reference commercial PMMA sheet specimen and other specimens at a wide HFOV, optical analysis including the effects of wavelength-specific optical absorptance not considered in Equation 4 suggests a $0.2 \%-0.3 \%$ reduction in transmittance if the thickness of the reference stock specimen was increased from $2.17 \mathrm{~mm}$ to $4.5 \mathrm{~mm}$. Thickness therefore cannot account for the difference in transmittance at the right of Figure 8 . Because the commercial specimen closely overlaps the theoretical $\tau_{\mathrm{d}}$, the composition (base PMMA material and corresponding reflectance from its refractive index) cannot explain the observed $\geq \sim 2 \%$ loss for the reference lenses relative to the commercial PMMA. After thickness and composition, the processes of optical absorption, backscattering, and wide-angle forward scattering as well as the ambient humidity remain to explain the reduced transmittance of the lens specimens relative to the reference stock specimen. These processes, all of which would be relevant in a CPV module, may follow from the limitations of the manual polishing process used to smooth the inside of the lens specimens after the facets were removed by milling. For example, the $\geq \sim 2 \%$ loss between the KACST-R-07 coupon and the theoretical $\tau_{\mathrm{d}}$ may follow from factors including surface waviness as well as the limited parallelism of the manual polishing of the faceted surface of the lens coupons.

\subsection{SUBSEQUENT COUPON EXAMINATIONS}

The AFM surface-roughness measurements for pieces of the lens specimens are summarized in Table 2. The table includes the details of the host site and its location, design of the lens, specimen history (for the references lenses or those fielded on a tracker), cleaning methodology, and measured roughness. Scratches were clearly evident for the warehouse (scrub-cleaned) lens, which has the most significant $R_{\mathrm{pv}}$. A lesser density of sizeable features - micrometers in width and millimeters in length-were observed on all specimens, except the stock-sheet PMMA. A smaller (on the order of $\sim 10$ s of nanometers) localized roughness was observed in many areas of the specimens. Areas of localized roughness were not as prevalent in AFM and SEM images of the warehouse specimen (additional data may be found in Ref. [44]). In addition to the differences in morphology, size, and distribution of features between the specimens, the measured roughness differs by as much as $\sim 2 \mathrm{x}$ 
between the test and reference specimens. The $R_{\mathrm{a}}$ and $R_{\mathrm{rms}}$ values for a polished lens surface (used to quantify haze in Figure 5, Figure 6, and Figure 7) were less than that of the fielded lenses and the wet-scrubbed reference lens. A network of scratches was readily observed in the microscopy of the milled and polished specimen. The surface roughness of all the lenses was at least $\sim 4 \mathrm{x}$ greater that of the stock-sheet PMMA specimen. Only nanoscale surface texture was observed for the stock-sheet specimen. No evidence of crazing or cracking into the surface of the lenses was observed in the AFM and SEM characterizations [44].

Regarding the large scratches on the warehouse lens, the majority likely follow from its known history of cleaning, including physical contact. It is not clear if the scratches observed on the other specimens result from handling or field-related abrasion. Regarding the localized nanoscale roughness, it could include both porosity and surface contamination, which can be difficult to distinguish between in AFM and SEM. Tenacious particulate and surface contamination can remain on field-soiled specimens [2]. The extent of the effect of the possible contamination of the AFM tip on the measurements is unknown. Still, the roughness values should be representative and are provided here for subsequent optical analysis of the transmittance. The $R_{\mathrm{a}}$ and $R_{\mathrm{rms}}$ come to approach the scale of one-quarter wavelength for visible light, which would be expected to overtly affect its propagation through horizontally aligned features. In the case of vertically aligned roughness, however, much smaller structures affect light propagation. For example, optical scattering on the order of $2 \%$ can follow from the $R_{\mathrm{rms}}$ of $10 \mathrm{~nm}$ at the wavelength of $631 \mathrm{~nm}$, Equation 7. The formula describes the scattered power at normal incidence for a monochromatic wave of light propagating from air into a dielectric medium [100]. Parameters in the equation include: the total integrated scatter (TIS, \%); the root-mean-square roughness $\left(R_{\mathrm{rms}}, \mathrm{m}\right)$; the index of refraction of the dielectric medium ( $n$, unitless); and the wavelength examined $(\lambda, \mathrm{m})$. The scratches evident on the warehouse specimen might additionally affect light propagation if they became dense enough to approach a periodic, i.e., grating, structure. The overall roughness of the milled and polished specimen is reduced relative to the veteran lenses, but is limited by the pattern of surface scratches remaining after the final grit used in polishing. The stock-sheet specimen provides a baseline for the minimal surface roughness that may be present for recently fabricated PMMA.

$$
T I S=100\left(1-\exp \left[-1 \cdot\left(\frac{2 \pi R_{r m s}(1-n)}{\lambda}\right)^{2}\right]\right)
$$


Regarding the surface roughness relative to other characterizations, the surface roughness of the milled and polished lens is reduced relative to the fielded lenses, which would explain the improved optical transmittance and reduced haze from the polishing of the faceted (bmp) then incident surfaces (bmp,fp) in Figure 5 and Figure 6. The roughness of the milled and polished lens exceeds that of the stock PMMA, which would explain the increased haze with the polishing of the faceted then incident surfaces of the reference lens in Figure 7. That is, the polishing process introduces surface scratches to both surfaces of the reference lens. The roughness of the lenses relative to the stock PMMA may contribute to the different transmittance observed for those specimens in Figure 8. Reduced optical scattering would be expected for the smoother stock PMMA specimen.

The results of cross-sectional microscopy are shown in Figure 9 for the incident surface of the lens and in Figure 10 for the faceted surface of the lens; the radius of the facet tips and groove valleys is summarized in Table 3. Figure 9 and Figure 10 primarily compare KACST-R-08 (the palletized reference) and KACST-O-08 (fielded on a tracker). A hash mark on the left of each image in Figure 9 indicates the location of the interface between the potting epoxy and the lens. The M-M lens specimen from APS is also shown in Figure 9, where voids on the order of tens of micrometers were observed. The observed porosity extends at least $1 \mathrm{~mm}$ on the surface of APS-O-08. Because the location of the epoxy/specimen interface is difficult to discern in the image, the true location of the interface may be closer to the top of the specimen than indicated in Figure 9. Other samples, including the APS Intersol lens, were not overtly affected other than local surface roughness (i.e., waviness) at high magnification. No evidence of crazing or cracking into the surface of the specimen was observed in the cross-sectional AFM and SEM characterizations.

Representative images of the facet tip and groove valley are shown in the insets of Figure 10. The valley radius was similar (within the margin of error) between all lenses examined. The tip radius, however, was less for the APS Intersol lens. Within the measurement variability, the tip radius for the APS M-M lens was also less than that of the KACST and warehouse lenses.

Regarding the porosity observed on the APS-O-08 lens surface in Figure 9, this readily explains the reduced $\eta_{\mathrm{o}}$ for the lens, where significant optical scattering would be expected based on the observed pore size. Further, the depth of the pores explains why the lens performance was not restored with polishing, which 
restored the $\eta_{\mathrm{o}}$ of the other veteran lenses. The pores in APS-O-08 may have formed when a volatile solvent locally dissolved the subsurface of the lens. For example, jet fuel or another chemical present at the Sky Harbor airport may have dissolved the subsurface of the APS-O-08 lens. The Intersol lenses, which were only fielded later at APS-STaR, would not have been affected by a chemical present at the Sky Harbor airport. The rounded morphology of the pores suggests that the damage results from material dissolution rather than from ESC. Only if a significant wind or other load were present might environmental stress cracking have contributed to the surface damage. Another possibility is that the pores were formed when the lens was manufactured, i.e., boiled material, where the machine processing pressure was too low.

The tip and groove radii of the KACST lenses were bigger than the intended $2.5-\mu \mathrm{m}$ prism radius, which would be expected to reduce lens performance. In comparison, the radius on contemporary lenses may approach 1 or $2 \mu \mathrm{m}$. The similar radii between test and reference specimens (KACST $20 \mathrm{y}$ relative to KACST reference and NREL warehouse), however, suggest that prism geometry cannot explain the measured loss in lens $\eta_{\mathrm{o}}$. To more thoroughly quantify the extent of optical loss from the prisms (e.g., blocking of light from total internal reflection or light scattering) would require a formal optical analysis, not examined here. Some of the variability in Table 3 results from the limited number of measurements (six) used in the experiment. Because the same (or similar) diamond tools are typically used to create the mold pattern, however, the tip radius should not vary significantly across the lens. Another factor affecting tip radius and its variability is the quality of the production run, which may depend on the machine condition, time of operation, operator, and other factors. Lastly, the smaller tip radii for the APS lenses suggest a different manufacturing vendor, which is consistent with the unique UV-VIS fluorescence spectra for those two lenses.

The results of the GPC analysis are summarized in Table 4, including the various molecular-weight parameters and the polydispersity. Measurements are compared between material sampled from the incident surface and the faceted surface of the lenses. The average difference between the faceted and incident surfaces for all specimens is identified at the bottom of Table 4. Regarding the measurements, the faceted-surface values (e.g., $M_{\mathrm{p}}$ and $M_{\mathrm{w}}$, which were used as reference values relative to the incident-surface values) are not particularly consistent, but typically exceed $80,000 \mathrm{~g} \cdot \mathrm{mol}^{-1}$. The average difference between the field-facing incident surface and module-interior-facing faceted surface is comparable for the field-aged KACST 20 y 
specimen and the KACST reference specimen. Regarding the molecular-weight distribution profiles, the similar PD values for all specimens identifies that their distribution of the molecular weight is similar, despite factors including specimen history and the surface location.

By reducing the molecular weight, UV chain scission of the surface can embrittle PMMA [2], which would make it more subject to fracture, crazing, or ESC. Veteran M-M lenses fielded in Phoenix that were subsequently steady-state weathered using a Xe source irradiance of $114 \mathrm{~W} \cdot \mathrm{m}^{-2}$ (for $300 \leq \lambda \leq 400 \mathrm{~nm}$ ), chamber temperature of $60{ }^{\circ} \mathrm{C}$, and $R H$ of $60 \%$ [43] demonstrated a change in molecular-weight parameters on the order of three times that of the difference between the faceted surfaces and incident surfaces in Table 4 [44]. Through the course of weathering, the artificial-aged specimens each developed a network of through-thickness cracks with significant cracking and spalling of the incident surface. The molecular-weight parameters for the incident surface of those specimens were on the order of 10,000, i.e., the embrittlement threshold where PMMA can no longer craze during deformation [2]. The limited difference in molecular weight between the incident surfaces and faceted surfaces relative to the discolored material in Ref. [43], however, suggests limited UV damage for the fielded veteran specimens.

The $M_{\mathrm{w}}$ for the veteran M-M lens fielded in Phoenix (obtained from the outer $100 \mu \mathrm{m}$ of the first surface in Table 4) is less than the $M_{\mathrm{w}}$ of $70,000 \mathrm{~g} \cdot \mathrm{mol}^{-1}$ obtained from the outer $200 \mu \mathrm{m}$ of the first surface of the veteran M-M specimens fielded in Phoenix in Ref. [10]. Although the analysis in Table 4 was performed using a different instrument, it is consistent with the depth profile for UV damage identified in Ref. [10], where the greatest damage would be expected at the incident surface. Regarding the $P D$ of the specimens Table 4, their similar values imply that UV damage at the irradiated surface occurs through the process of random chain scission.

Regarding the $M_{\mathrm{w}}$ of unaged PMMA, the $M_{\mathrm{w}}$ for the NREL warehouse specimen in Table 4, which was stored in a dark wooden box through much of its life, exceeds $100,000 \mathrm{~g} \cdot \mathrm{mol}^{-1}$. Ref. [10], which examines material sectioned from within the bulk of the veteran M-M lens fielded in Phoenix, suggests that $M_{\mathrm{w}}$ may approach $110,000 \mathrm{~g} \cdot \mathrm{mol}^{-1}$. This value might be used to interpret Table 4 . The value of $110,000 \mathrm{~g} \cdot \mathrm{mol}^{-1}$, however, exceeds the molecular-weight values in Table 4 for the faceted surface of the lenses. 
Factors that might explain the variety of molecular weights obtained for the faceted surface of the lens include: the make and formulation of material (additional characterization suggests that the APS-STaR lenses are different than the other lenses); through-thickness UV damage; leaking of light to the faceted surface around the edges of the lens (particularly for the palletized KACST reference lenses); and damage to the material during lens fabrication. It is presently unknown which (if any) of these factors apply to the lenses in Table 4.

\section{DISCUSSION}

M-M anticipated a lens design with an $\eta_{\mathrm{o}}$ of $85 \%$ [33], subject to UV degradation at the rate of $1 \%$ per decade [27]. Although the $\eta_{\mathrm{o}}$ of $\sim 85 \%$ was observed in Table 1 for the reference specimens, an $\sim 10 \%$ loss in performance was observed for the $\sim 20$-year veteran lenses. The series of measurements above can be used to identify the damage mode(s) most significantly reducing the $\eta_{\mathrm{o}}$ of the veteran lenses.

The curvature of the lenses, which is convoluted with the lens $\eta_{\mathrm{o}}$ measurement because of the folded MM lens design, provides a limited effect on $\eta_{\mathrm{o}}$. A modest magnitude of effect follows from the comparison of the measurements for the entire lens and the lens center in Table 1, where little change in $\eta_{\mathrm{o}}$ with the focal distance is observed for the masked lenses. For a CPV module, curvature may be reduced further by the added physical constraints occurring when the lens is mechanically mounted to the module. Curvature might be further reduced by the module designer by using a thicker lens. Lens curvature, however, is undesirable in CPV because it can introduce effects and subsequent losses at each cell; mismatch between cells can be amplified by the range of curvatures intrinsic to different lenses as well as the tolerance of alignment and assembly of the lenses to the module.

Comparison of the wavelength-specific results in Figure 4, where the $\eta_{\mathrm{o}}$ of the veteran lenses in the shorter-wavelength hot-mirror results is less than the $\eta_{\mathrm{o}}$ of the longer-wavelength cold-mirror measurements, suggests that the performance of the veteran lenses is reduced by optical scattering. Subsequent measurements were performed on milled and polished specimens to successively remove the effects of the lens facets and roughness present on the incident surface. The spectrophotometer measurements (including Figure 5, Figure 6, and Figure 7) further confirm loss of $\eta_{\mathrm{o}}$ from optical scattering, quantifying the magnitude of loss as a function of wavelength. The spectrophotometer measurements importantly do not identify significant optical absorption from discoloration, which may vary significantly with the formulation of PMMA used in the lens [43]. The 
VLABS measurement, Figure 8, confirms the significance of optical scattering. Figure 8 is also a reminder of the detrimental effect of optical-haze generation in CPV systems, which cannot harvest diffuse light because of their limited acceptance angle.

The subsequent characterizations in this study provide perspective on the source of optical scattering for the veteran lenses. The vertical surface roughness is observed in

to be increased on the order of 10 s of nanometers, sufficient to cause optical scattering. Voids as large as 100 s of nanometers in diameter were uniquely observed in Figure 9 for the incident surface of the veteran MM lens fielded in Phoenix. Although these features might explain the substantial optical scattering and reduced optical transmittance of that specimen, no similar features were observed in any of the other lens specimens. Tip radii larger than intended were observed at the prism tip and valley in Table 3, but there was no strong distinction between the veteran and reference lenses to suggest an increase in radius and corresponding optical scattering with age. The operating temperature for the veteran lenses is believed to be well below the glasstransition temperature of PMMA, which would prevent physical aging from contributing to facet rounding. Some decrease in molecular weight from UV aging is implied in Table 4 from the comparison of the incident and faceted surfaces of the lenses, but no critical loss of molecular weight, approaching the threshold for material embrittlement, was observed. The lack of cracking or crazing in AFM and cross-sectional microscopy as well as the less-than-critical decrease in molecular weight suggest that crazing, microcracking, and ESC do not contribute to optical scattering for the lens specimens. The majority of the decrease in optical performance for the veteran lenses is therefore likely caused by the abrasion and subsequent roughening of the incident surface of the lenses. It should be noted that soiling-where a thin base layer can become effectively permanently bound to the incident surface [2] — is not examined in this study. Soiling could also contribute to optical scattering based on the added surface roughness of the layer of accumulated material in addition to the optical characteristics of the surface contamination, i.e., increased absorptance, reflectance, and scattering. Welladhered contamination on the Intersol lenses at APS-STaR (the only lenses that were not cleaned through their use) may contribute to their greater surface roughness and/or optical scattering. 
An increase in the surface roughness of the veteran lenses may follow from abrasion of their first surfaces. It remains to be established if natural erosion from the environment or artificial abrasion (e.g., from cleaning for site maintenance) typically dominates the abrasion of CPV installations. From

, it might be expected that natural erosion most affects the veteran lenses in this study because of the non-contact methods used to clean the lenses. Regarding the dominant source of abrasion, the industry presently lacks PV-specific abrasion test method(s). Popular methods in other industries (including falling sand, forced sand impingement, and machine abrasion tests) are, however, reviewed in Ref. [101].

Based on the examinations here, the damage to the lenses appears to occur primarily at their first surfaces, rather than in the bulk of the material. Especially for PMMA lenses, degradation including surface roughness, surface contamination, and near-surface UV damage can be reduced by polishing the first surface. The literature suggests that mechanical polishing or chemical etching is specifically required [2] to remove welladhered surface contamination from PV first surfaces. Although the technical feasibility of mechanical polishing has been demonstrated in Ref. [102], the economics remain to be analyzed. The cost/benefits may depend on site-specific factors, including damage rate and corresponding required frequency of polishing as well as proximity of the installation to maintenance resources.

\section{CONCLUSIONS}

The optical performance of lenses from veteran CPV modules was examined after the end of their service life. A reduction in optical efficiency of greater than $10 \%$ was observed for some lenses. Therefore, the lenses were subjected to further study to better quantify their optical performance and to identify the responsible degradation mode(s).

The most significant optical loss followed from light scattering. Scattering was found to result from roughening of the incident surface, not to a change in the radius of the prism tips or valleys. Based on AFM and SEM, as well as the known cleaning history of the installation sites (spray-clean only), natural abrasion is identified as roughening the surface of the veteran lenses studied here. The measured roughness of the lens specimens was increased by 10 s of nanometers, being at least $\sim 4 \mathrm{x}$ that of the surface of a fresh PMMA stock specimen. Although it was not examined here, soiling of the first surface may also contribute to optical scattering through increased roughness as well as optical effects. Well-adhered contamination on the Intersol lenses at APS-STaR (the only lenses that were not cleaned through their use) may contribute to their greater 
surface roughness and/or optical scattering. Change in curvature of the lenses (and their corresponding focal distance) was observed, but the optical effect was not significant for the central portions of the lens, where the folded optical design used in the M-M modules was absent.

From the additional examinations, several degradation modes were found to be irrelevant to the veteran lenses examined here. With minimal rounding of the optical cut-on profile discoloration and consequent optical absorption did not significantly contribute to the reduced optical efficiency of the veteran lenses. With minimal shift in the UV cut-off wavelength, the PMMA formulation was found to be stable through the service life. Verification of material stability by using accelerated-weathering testing could help ensure similar results for contemporary PMMA formulations. Crazing, microcracking, and environmental stress cracking also did not significantly contribute to the reduced optical efficiency of the veteran lenses. No evidence of these modes was observed in surface microscopy (AFM and SEM) or cross-sectional examinations (optical and SEM). Furthermore, although random UV-facilitated chain scission is implied from the lesser molecular weight at the incident surface of the lenses, the observed molecular weights were not below the threshold of $10,000 \mathrm{~g} \cdot \mathrm{mol}^{-1}$ for weight-averaged molecular weight typically found to embrittle the PMMA, readily facilitating crazing or cracking.

Voids extending below the first surface were found to reduce the optical efficiency of the veteran Martin-Marietta lenses fielded in Phoenix. Many of the voids, approaching hundreds of nanometers in size and extending hundreds of micrometers into the surface, were not removed after polishing the incident surface. The voids may uniquely follow from solvent interaction, possibly occurring during the sample's brief history of deployment at the Phoenix Sky Harbor airport. None of the veteran lenses from other locations demonstrated the same coarse surface porosity.

\section{ACKNOWLEDGEMENTS}

The authors are grateful to: Dr. Jeffrey Blackburn, Dr. James Burst, Dr. Mike Kempe, Dr. Matthew Gray, Dr. Daryl Myers, Dr. John Pern, Kate Baughman, Greg Perrin, Ian Tappan at NREL; F.M. Al-Alweet, A. Alyahya, N. Eugenio, M. Halawani, A. Al Owais, at the KACST Saudi National Research Center; Peter Jakob, Philipp Lindner, and Thomas Schmidt at Fraunhofer ISE; Howard Barikmo, Tom Lepley, Michael Longyear, Joe McGuirk, Scott Steele, and John Wiedner of the former APS-STaR center; Sidney Broadbent, and David Hughes of the former Martin-Marietta Corporation; and Eldon Boes, Mike Edenburn, Olga Lavrova, and Charlie 
Stillwell of Sandia National Laboratories. A special thanks is extended to Joe McGuirk, Sidney Broadbent, David Hughes, Eldon Boes, Mike Edenburn, and Charlie Stillwell who were able to provide feedback at the time of writing concerning their experiences with the Martin-Marietta CPV technology. This work was supported by the U.S. Department of Energy under Contract No. DE-AC36-08GO28308 with NREL as well as the

Comunidad de Madrid through the program MADRID-PV-CM (S2013/MAE2780) with IES-UPM.

\section{REFERENCES}

1. A. Luque, S. Hegedus (editors), Handbook of Photovoltaic Science and Engineering, John Wiley \& Sons Inc.: Hoboken, 2003, 449-500.

2. D.C. Miller, S.R. Kurtz, Durability of Fresnel lenses: A review specific to the concentrating photovoltaic application, Solar Energy Mater. Solar Cells, 95 (2011), 2037-2068.

3. D.C. Miller, M.D. Kempe, C.E. Kennedy, S.R. Kurtz, Analysis of transmitted optical spectrum enabling accelerated testing of multi-junction CPV designs, Opt. Eng., 50 (1), 2010, 013003.

4. F. Ruesch, S. Brunold, Ageing performance of collector glazing materials-results from 20 years of outdoor weathering, in: Proceedings of the Eurosun Conference, (2008).

5. D.C. Miller, L.M. Gedvilas, B. To, C.E. Kennedy, S.R. Kurtz, Durability of poly(methyl methacrylate) lenses used in concentrating photovoltaics, Proc. SPIE, 2010, 7773-02.

6. H. Gomez, G.S. Kinsey, A. Nayak, H. Oba, CPV reliability program at AMONIX Inc., Proc. Int. Conf. CPV, 2011, 327-330.

7. M.P. Murray, D. Gordon, S.A. Brown, W.-C. Lin, K.A. Shell, M.A. Schuetz, S. Fowler, J. Elman, R. H. French, Solar radiation durability framework applied to acrylic solar mirrors, Proc. SPIE, 2011, 8112-01.

8. C. Algora, P. Espinet, M. Vázquez, N.S. Bosco, D.C. Miller, S.R. Kurtz, F. Rubio, R. McConnell, "Chapter 9: Reliability," in Handbook of Concentrator Photovoltaic Technology, John Wiley \& Sons Inc.: Hoboken, 2016.

9. D.C. Miller, L.M. Gedvilas, B. To, C.E. Kennedy, S.R. Kurtz, "Durability of poly(methyl methacrylate) lenses used in concentrating photovoltaics," Proc. SPIE, 2010, 7773-02.

10. D.C. Miller, T. Arndt, R. Kogler, "Characteristics of a veteran acrylic lens relative to acrylic lens materials after accelerated laboratory weathering," Proc. $11^{\text {th }}$ International Conference on Concentrator Photovoltaic Systems (Aix-les-Bains, France), 2015.

11. M.O. Nazer, Photovoltaic concentrator power station for a village in Saudi Arabia, Proc. Euro PVSEC, 1980, 368-374.

12. J.J. Fendley, Solar energy in Saudi Arabia: The SolERAS project, Energy Digest, 1982, 8-15.

13. F.S. Huraib, B.H. Khoshaim, A. Al-Sani, M.S. Imamura, A.A. Salim, Design installation and initial performance of 350-kW photovoltaic power system for Saudi Arabian villages, Proc. Euro PVSEC, 1982, 57-66. 
14. F.S. Huraib, A. Al-Sani, B.H. Khoshaim, Operational results from the Saudi solar village photovoltaic power system, Proc. IEEE IECEC, 1982, 1531-1534.

15. B.H. Khoshaim, F.S. Huraib, A. Al-Sani, A.A. Salim, Eighteen-month performance of $350 \mathrm{~kW}$ PVPS for Saudi Arabian villages, Proc. IEEE IECEC, 1983, 1278-1283.

16. B.H. Khoshaim, F.S. Huraib, A. Al-Sani, A.A. Salim, Performance of $350 \mathrm{~kW}$ concentrating photovoltaic power system after two years, Proc. Euro PVSEC, 1983, 207-214.

17. B.H. Khoshaim, F.S. Huraib, A. Al-Sani, A.A. Salim, M.S. Imamura, Performance of $350 \mathrm{~kW}$ photovoltaic power system for Saudi Arabian villages after 30 months, Proc. IEEE PVSC, 1984, 1426-1432.

18. A. Bowen, S.A. Balto, A. Al-Saief, Photovoltaic electrification of 3 villages in Saudi Arabia, Proc. PLEA Conf., 1985, 837-848.

19. A.A. Salim, F.S. Huraib, B.H. Khoshaim, N.N. Eugenio, N.R. Rao, Four year performance summary of 350 kW concentrating photovoltaic power system, Proc. IEEE PVSC, 1985, 1545-1552.

20. A.A. Salim, F.S. Huraib, B.H. Khoshaim, N.N. Eugenio, N.R. Rao, M.S. Imamura, Performance characteristics of the $350 \mathrm{~kW}$ concentrator photovoltaic array field, Proc. IEEE IECEC, 1986, 1285-1291.

21. F.S. Huraib, A.A. Salim, The first interconnection of a solar photovoltaic power system with the utility grid in Saudi Arabia, Proc. Symp. Electr. Power Fast Develop. Countries, 1987, 512-515.

22. A.A. Salim, F.S. Huraib, N.N. Eugenio, T.C. Lepley, Performance comparison of two similar concentrating PV systems operating in the U.S. and Saudi Arabia, Proc. IEEE PVSC, 1987, 1351-1357.

23. A.A. Salim, N.N. Eugenio, A comprehensive report on the performance of the longest operating $350 \mathrm{~kW}$ concentrator photovoltaic power system, SOLMAT, 29 (1990), 1-24.

24. M.S. Smiai, S. Al-Awaji, Performance of a $350 \mathrm{~kW}$ photovoltaic concentrator field (in operation since 1981), Proc. Euro. PVSEC, 1992, 1340-1343.

25. S.H. Alawaji, Evaluation of solar energy research and its applications in Saudi Arabia - 20 years of experience, Renew. Sustain. Energy Rev., 5 (2001), 59-77.

26. Photovoltaic Concentrator Technology Development Project: First Project Integration Meeting, SAND-780374, 1978, 1-151.

27. R.L. Donovan, S. Broadbent, 10-Kilowatt photovoltaic concentrator array, SAND78-7024, 1978, 1-194.

28. Photovoltaic Concentrator Technology Development Project: Second Project Integration Meeting, SAND78-0988, 1978, 1-227.

29. Photovoltaic Concentrator Technology Development Project: Third Project Integration Meeting, SAND-790557, 1979, 1-141.

30. Photovoltaic Concentrator Technology Development Project: Fourth Project Integration Meeting, SAND79-1791, 1979, 1-347.

31. Photovoltaic Concentrator Technology Development Project: Fifth Project Integration Meeting, SAND-800852, 1980, 1-337.

32. Photovoltaic Concentrator Technology Development Project: Sixth Project Integration Meeting, SAND-802373, 1980, 1-298.

33. J.A. Sanders, R.L. Donovan, S. Broadbent, 10-kilowatt photovoltaic concentrator fabrication, SAND807062, 1980, 1-294. 
34. N. Sharma, Airport solar photovoltaic concentrator project, DOE-CS-05317-1, 1979, 1-335.

35. W.J. McGuirk, Solar photovoltaic concentrator project at Sky Harbor airport, Proc. ASME ASPCP Conf., 1982, 1-6.

36. W.J. McGuirk, Phase II fabrication and construction of the Sky Harbor airport solar photovoltaic concentrator project, DOE-ET-20624-1, 1984, 1-60.

37. R. Taylor, P. Pittman, J. McGuirk, S. Carlisle, R. Megerle, R. Spencer, M. Anderson, E. Simburger, V. Wilreker, Photovoltaics generation - Recent technology advancements, IEEE Trans. Power Apparat. Syst. Vol. PAS-104, 1985, 2962-2970.

38. T. Lepley, Sky Habor photovoltaic concentrator project. Phase III: First forty-two months of operation, DOE-ET-20624-T14, 1986, 1-83.

39. G. Sala, A.L. Luque, Past experience and new challenges of PV concentrators, in A.L. Luque and V.M. Andreev, Concentrator Photovoltaics, Springer: New York, 2007.

40. S. Boradbent, J.E. Baumann, B.W. Heler, D.J. Hughs, L.S. Marshall, R.P. Semma, R.E. Stegeman, Second generation photovoltaic concentrator array design, SAND82-7133, 1982, 1-321.

41. J.A. Sanders, Design of photovoltaic central power station concentrator array, SAND82-7148, 1982, 1-255.

42. S. Broadbent, J.A. Sanders, Development and fabrication of photovoltaic concentrator modules for a pointfocus Fresnel lens array, SAND85-7001, 1985, 1-76.

43. D.C. Miller, J.D. Carloni, D.K. Johnson, J.W. Pankow, E.L. Gjersing, B. To, C.E. Packard, C.E. Kennedy, S.R. Kurtz, An investigation of the changes in poly(methyl methacrylate) specimens after exposure to ultraviolet, heat, and humidity, Solar Energy Materials and Solar Cells, 111, 2013, 165-180.

44. D.C. Miller, H.I. Khonkar, R. Herrero, I. Antón, D.K. Johnson, T. Hornung, T. Schmid, T.B. Vinzant, B. To, G. Sala, S.R. Kurtz, An end of service life assessment of PMMA lenses from veteran concentrator photovoltaic systems, NREL-PR-5J00-67733, 2017.

45. Y. Bokoi, C. Ishiyama, M. Shimojo, Y. Shiraishi, Y. Higo, Effects of sorbed water on crack propagation in poly)methyl methacrylate) under static tensile stress, J. Mats. Sci., 35, 2000, 5001-5011.

46. G.P. Marshall, J.G. Williams, Craze growth in PMMA under cyclic loads, J. Appl. Polym. Sci., 17, 1973, 987-1005.

47. G.W. Weidmann, W. Döll, Interferenzoptische vermessung der craze-zone vor der rißspitze in PMMA unterschiedlichen molekulargewichtes, Colloid Polym. Sci., 254, 1976, 205-214.

48. M.I. Bessonov, E.V. Kuvshinskii, The kinetics of the growth of "silver" cracks in transparent solid polymers, Sov. Phys.-Sol. State, 3 (5), 1961, 950-957.

49. R.P. Kambour, Mechanism of fracture in glassy polymers: I. Fracture surfaces of polymethyl methacrylate, J. Polym. Sci. A3, 1965, 1713-1724.

50. R.P. Kambour, Mechanism of fracture in glassy polymers. III: Direct observation of the craze ahead of the propagating crack in poly(methyl methacrylate) and polystyrene, J. Polym. Sci. A-2, 4, 1966, 349-358.

51. H.R. Brown, I.M. Ward, Craze shape and fracture in poly(methyl methacrylate), Polym. 14, 1973, 469-475. 
52. L. Bevan, Crazing under applied compression, J Mats. Sci. Lett., 13, 1978, 216-217.

53. L. Bevan, H. Nugent, Residual craze and crack formation in poly(methyl methacrylate), Polym. Eng. Sci., 23 (4), 1983, 211-215.

54. B.E. Read, G.D. Dean, Time-dependent deformation and craze initiation in PMMA: Volume effects, Polym., 25, 1984, 1679-1686.

55. L. Xiu, Strain-amplitude and strain-rate dependent craze damage of poly(methyl methacrylate), Polym. Polym. Comp. 22 (8), 2014, 737-741.

56. S.S. Sternstein, L. Ongchin, Yield criteria for plastic deformation of glassy high polymers in general stress fields, Polym. Prepr. Am. Chem. Soc. Div. Polym. Chem., 10, 1969, 1117-1124.

57. S.S. Sternstein, F.A. Myers, Yielding of glassy polymers in the second quadrant of principal stress space, J. Macromol. Sci. Phys., B8, 1973, 539-571.

58. E.H. Andrews, G.M. Levy, Solvent stress crazing in PMMA: 1. Geometrical effects, Polym., 15, 1974, 599607.

59. M. Kawagoe, M. Kitagawa, Craze initiation in poly(methyl methacrylate) under biaxial stress, J. Polym. Sci., 19, 1981, 1423-1433.

60. P.J. Burchill, R.H. Stacewicz, Effect of water on the crazing of a crosslinked poly(methyl methacrylate), J Mats. Sci. Lett., 1982, 448-450.

61. W. Döll, L. Könczöl, M.G. Schinker, Size and mechanical properties of craze zones at propagating crack tips in poly(methyl methacrylate) during fatigue loading, Polym., 24, 1983, 1213--1219.

62. P.D. Washabaugh, W.G. Knauss, Non-steady periodic behavior in the dynamic fracture of PMMA, Int. J. Fract., 59, 1993, 189-197.

63. G. Pulos, W.G. Knauss, Nonsteady crack and craze behavior in PMMA under cyclical loading: I. Experimental preliminaries, Int. J. Fract., 93, 1998, 145-159.

64. G. Pulos, W.G. Knauss, Nonsteady crack and craze behavior in PMMA under cyclical loading: II. Effect of load history on growth rate and fracture morphology, Int. J. Fract., 93, 1998, 161-185.

65. G. Pulos, W.G. Knauss, Nonsteady crack and craze behavior in PMMA under cyclical loading: III. Effect of load history on cohesive force distribution on the craze, Int. J. Fract., 93, 1998, 187-207.

66. G.P. Marshall, L.E. Culver, J.G. Williams, Craze growth in polymethylmethacrylate: A fracture mechanics approach, Proc. Roy. Soc. Lond., A319, 1970, 165-187.

67. Y.W. Mai, On the environmental fracture of polymethylmethacrylate, J. Mats. Sci., 10, 1975, 943-954.

68. Y. Imai, N. Brown, Environmental crazing and intrinsic tensile deformation in polymethylmethacrylate, J Mats. Sci., 11, 1976, 417-424.

69. D. Pütz, G. Menges, The influence of liquid environmental media on the mechanical behavior of thermoplastics, Brit. Polym. J. 10, 1978, 69-73.

70. J.M. Barton, Effect of absorbed water on the thermal relaxation of biaxially stretched crosslinked poly(methyl methacrylate), Polym., 20, 1979, 1018-1024. 
71. R.G. Hill, J.F. Bates, T.T. Lewis, N. Rees, The fracture of acrylic polymer sin water, J. Mats. Sci, 19, 1984, 1904-1916.

72. J. Shen, C.C. Chen, J.A. Sauer, Effects of sorbed water on properties of low and high molecular weight PMMA: 1. Deformation and fracture behavior, Polym., 26, 1985, 511-518.

73. L.S.A. Smith, J.A. Sauer, Sorbed water and mechanical behavior of poly(methyl methacrylate), Plast. Rubber Proc. Apps., 6 (1), 1986, 57-65.

74. M. Kawagoe, M. Kitagawa, Environmental crazing and cracking in poly(methyl methacrylate) under diametral compression, J. Mats. Sci., 25, 1990, 1043-1049.

75. L. Josserand, R. Schirrer, Influence of water on crack propagation in poly methyl methacrylate: Craze stress and craze fibril lifetime, J. Mats. Sci, 30, 1995, 1772-1780.

76. C. Ishiyama, Y. Shirashi, M. Shimojo, Y. Higo, Effects of humidity on creep fracture and crazing behavior of PMMA, Proc. Intl. Conf. Frac., 1997, 1029-1035.

77. J.C. Arnold, The effects of diffusion on environmental; Stress crack initiation in PMMA, J. Mats. Sci., 33, 1998, 5193-5204.

78. C. Ishiyama, T. Sakuma, M. Shimojo, Y. Higo, Effects of humidity on environmental stress cracking behavior in poly(methyl methacrylate), J. Polym. Sci., 40B, 2002, 1-9.

79. O.A. Pringle, R.J. Harker, Environmental fatigue testing of molded plastics for prothetic heart valves, Exp. Mech., 9 (4), 1969, 171-178.

80. Y.W. Mai, Fatigue crack propagation of PMMA in organic solvents, J. Mats. Sci. Lett., 9, 1974, 1896-1898.

81. C.C. Chen, J. Shen, J.A. Sauer, Effects of sorbed water on properties of low and high molecular weight PMMA: 11. Fatigue performance, Polym., 26, 1985, 89-96.

82. R. Schirrer, L. Josserand, P. Davies, Fracture surface energy and craze fibril stress in PMMA in water, J. de Physique IV, 3 (C7), 1993, 1553-1557.

83. Z.-D. Li, H.-J. Liu, R.-F. Zhang, H. Yi, Time-temperature-stress superposition principle of PMMA's crazing damages under creep condition, J. Cent. South Univ. Technol., 2007, 318-323.

84. J. Hennig, Spannungsrissverhalten von PMMA nach freibewittrung, die Ange. Makromol. Chemie, 114, 1983, 131-139.

85. V. Altstädt, Intrinsic Molecular Mobility and Toughness of Polymers II, Springer-Verlag: New York, 2005, $126-132$.

86. D.T. Turner, Polymethyl methacrylate plus water: sorption kinetics and volumetric changes, Polym., 23, 1982, 197-202.

87. D.C. Miller, M.T. Muller, M.D. Kempe, K. Araki, C.E. Kennedy, S.R. Kurtz, Durability of polymeric encapsulation materials for concentrating photovoltaic systems, Progress in Photovoltaics: Research and Applications, 21 (4), 2013, 631-651.

88. C. Domínguez, I. Antón, G. Sala, Solar simulator for concentrator photovoltaic systems, Optics Express, 16(19), 2008, 14894-14901. 
89. S. Askins, Effects of temperature on hybrid lens performance, AIP Conf. Proc. 1407, 57-61 (2011).

90. I. Anton, C. Dominguez, R. Herrero, S. Askins, M. Victoria, G. Sala, Advances in indoor characterization of CPV modules and components, Jap. J. Appl. Phys. 51, 2012, 10ND12-1-10ND12-4.

91. R. Herrero, C. Domínguez, S. Askins, I. Antón, G. Sala, Methodology of quantifying curvature of Fresnel lenses and its effect on CPV module performance, Opt. Express 23, A1030-A1039 (2015).

92. IEC 60904-3: Photovoltaic devices. Part 3: Measurement principles for terrestrial photovoltaic (PV) solar devices with reference spectral irradiance data. International Electrotechnical Commission: Geneva, (submitted).

93. M. Victoria, S. Askins, R. Herrero, I. Antón, G. Sala, Assessment of the optical efficiency of a primary lens to be used in a CPV system, Solar Energy, 134, 2016, 406-415, http://dx.doi.org/10.1016/j.solener.2016.05.016.

94. IEC 62788-1-4: Measurement procedures for materials used in photovoltaic modules - Part 1-4: Encapsulants - Measurement of optical transmittance and calculation of the solar-weighted photon transmittance, yellowness index, and UV cut-off frequency, International Electrotechnical Commission: Geneva, (submitted).

95. D.C. Miller, J. Apezteguia, J.G. Bokria, M. Köhl, N.E. Powell, M.E. Smith, M.D. White, H.R. Wilson, J.H. Wohlgemuth, Examination of an optical transmittance test for photovoltaic encapsulation materials, Proc. SPIE 2013, 8825-8.

96. D.C. Miller, J. Apezteguia, J.G. Bokria, M. Köhl, N.E. Powell, M.E. Smith, M.D. White, H.R. Wilson, J.H. Wohlgemuth, Examination of an optical transmittance test for photovoltaic encapsulation materials, NREL/PR-5200-60379, 2013, 1-24.

97. A. Heimsath, T. Schmid, P. Nitz, Angle resolved specular reflectance measured with VLABS, Proc. Int. Conf. Concentrating Solar Power Chem. Energy Syst. (SolarPACES 2014), Energy Procedia, 69, 2015 , 1895-1903, doi: 10.1016/j.egypro.2015.03.173.

98. R. Leutz, A. Suzuki, Nonimaging Fresnel Lenses: Design and Performance of Solar Concentrators, Springer-Verlag: New York, 2001.

99. D.C. Miller, M.D. Kempe, M.T. Muller, M.H. Gray, K. Araki, S.R. Kurtz, Durability of polymeric encapsulation materials in a PMMA/glass concentrator photovoltaic system, submitted to Solar Energy Materials and Solar Cells.

100. C.K. Carniglia, “Scalar scattering theory for multilayer optical coatings,'” Opt. Eng. 18, 104-115 (1979).

101. D.C. Miller, M.T. Muller, L.J. Simpson, Review of artificial abrasion test methods for PV module technology, NREL/TP-5J00-66334, 2016, 1-25.

102. T. Arndt, P. Battenhausen, P. Kilian, R. Sättler, Polishing acrylic lens materials after sand impact, AIP Conf. Proc. 1556, 2013, 67-70. 
Figures:
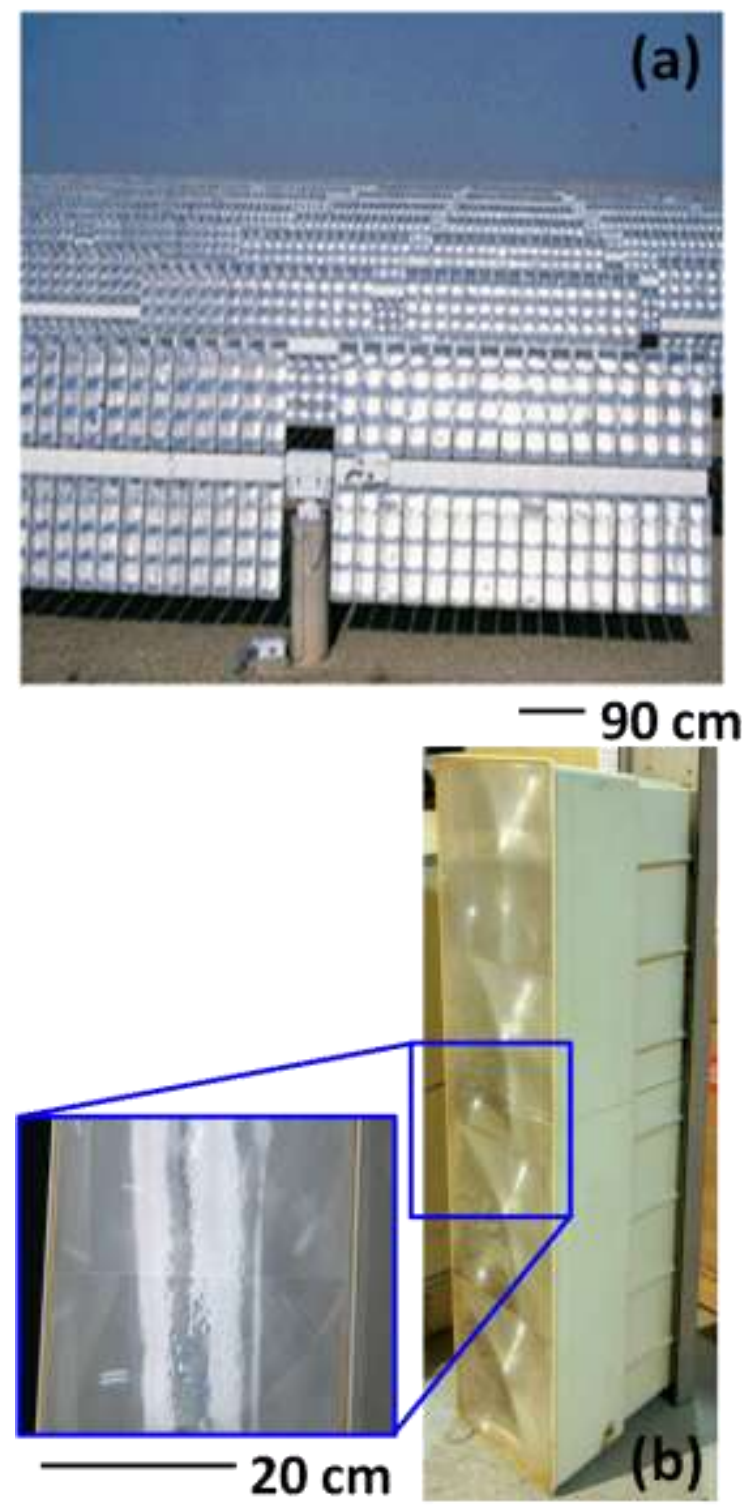

Figure 1: Photographs of (a) the Solar Village system, and (b) a Martin-Marietta module (from the NREL warehouse). The dimpled surface of the lens may be observed in the speckled reflection of the overhead lights in the inset of (b). 


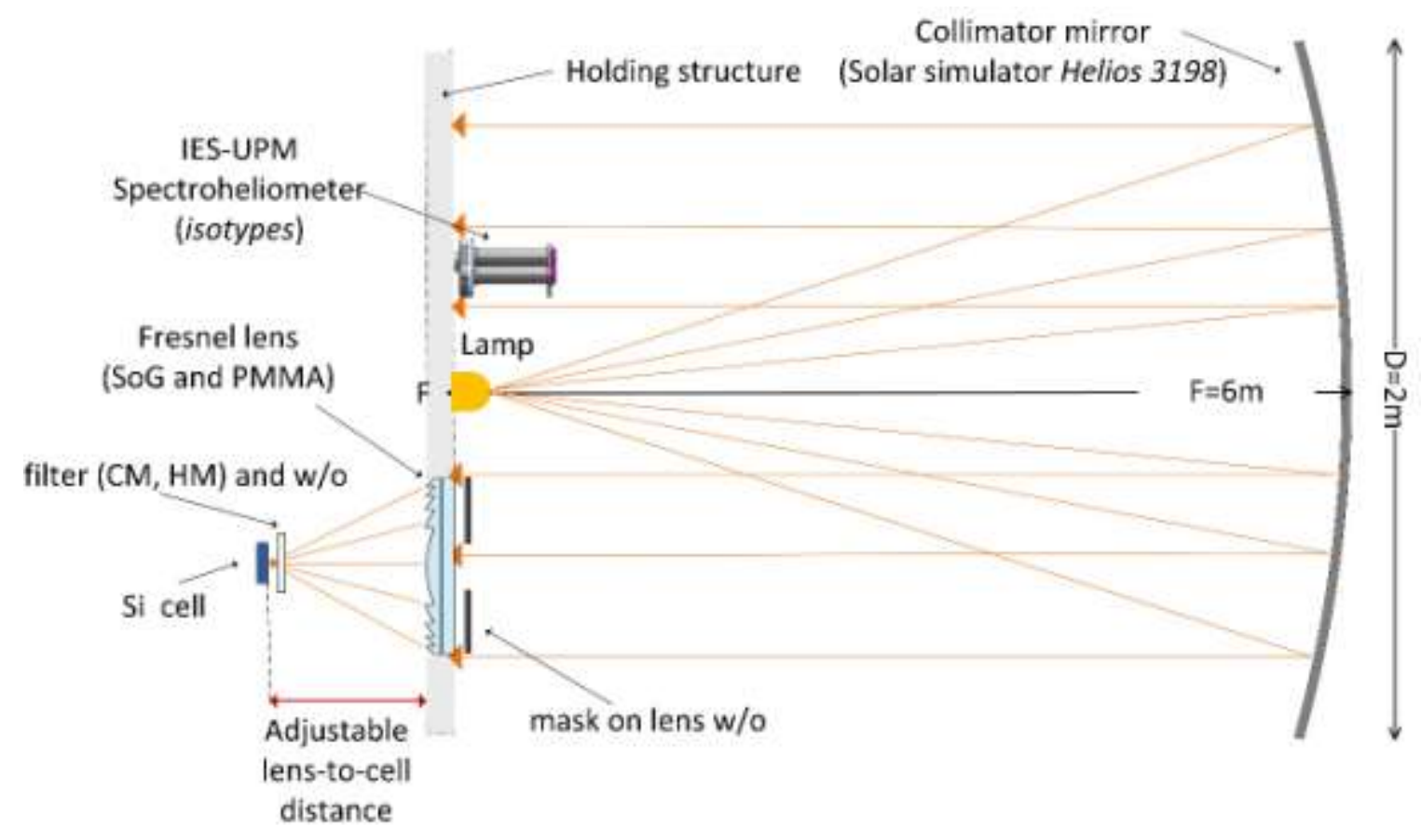

Figure 2: Cross-sectional schematic depicting the key components and use of the IES-UPM CPV Solar Simulator for measuring optical efficiency of a veteran lens.

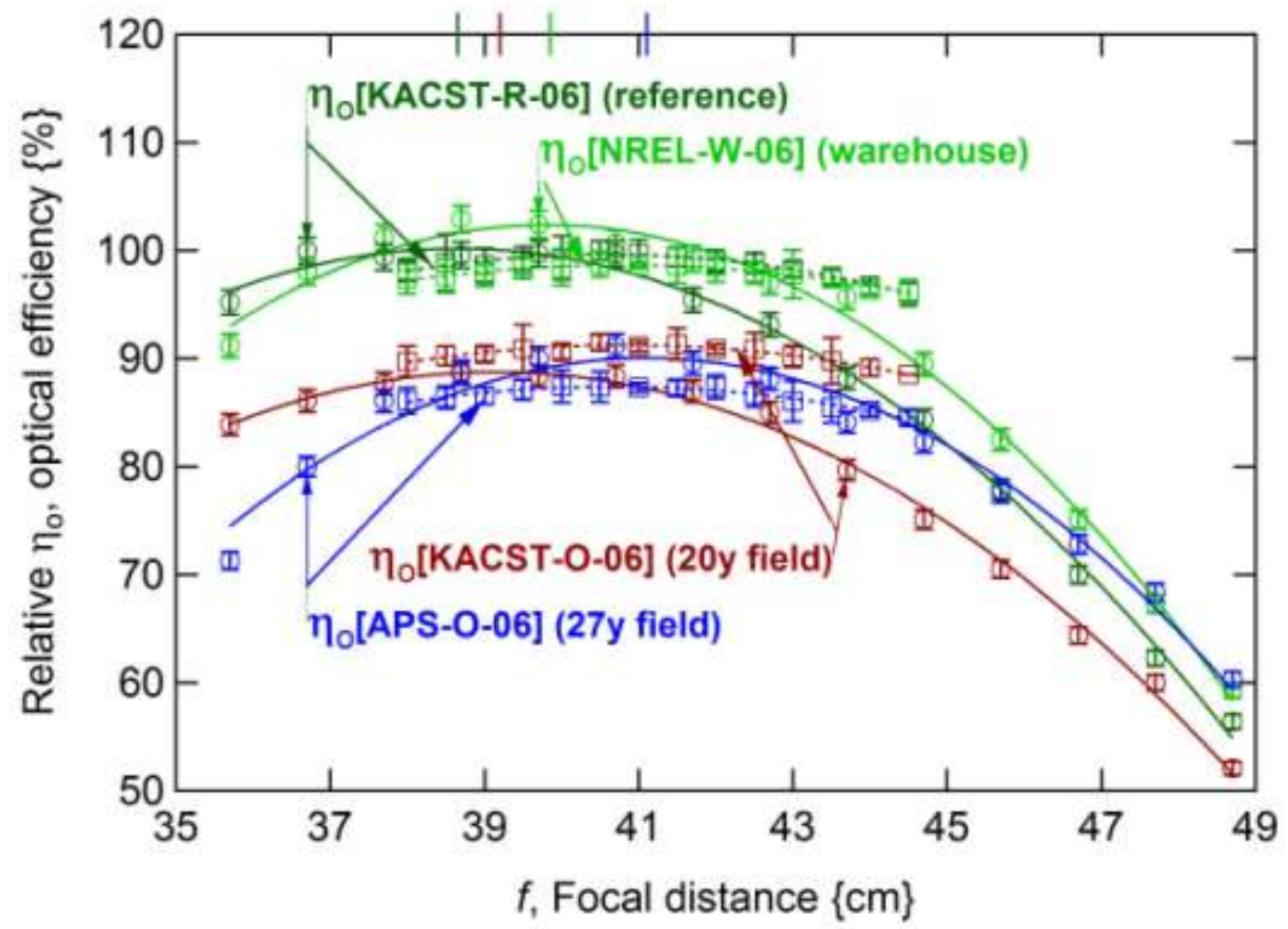

Figure 3: Comparison of the relative optical efficiency of the lenses ( \pm 2 S.D., normalized to KACST-R-06) as a function of focal distance. Scans for the entire (unmasked) lens are indicated using a circle with best fits using solid lines; scans for the lens center ( $8 \mathrm{~cm} \times 8 \mathrm{~cm}$ mask) are shown using squares with best fits using dashed lines. 


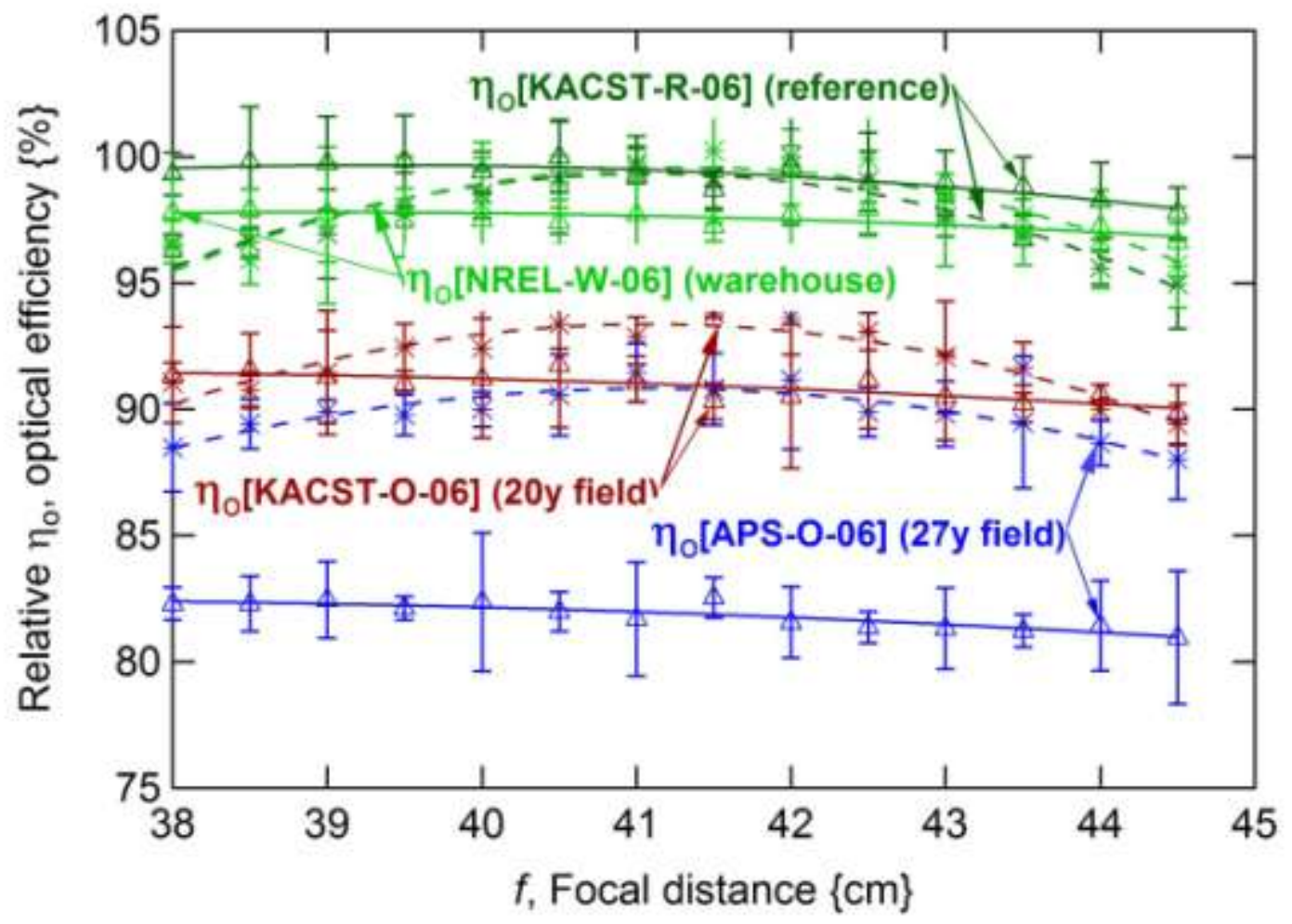

Figure 4: Comparison of relative $\eta_{\mathrm{o}}$ for the center of the lenses $( \pm 2$ S.D., $8 \mathrm{~cm} \times 8 \mathrm{~cm}$ mask, normalized to KACST-R-06) as a function of focal distance. Scans were obtained using the Si cell with the hot mirror (corresponding spectral bandwidth of 390-750 nm, indicated using a triangle with best fits using solid lines), or the cold mirror (675-1,150 nm, shown using asterisk and dashed lines).

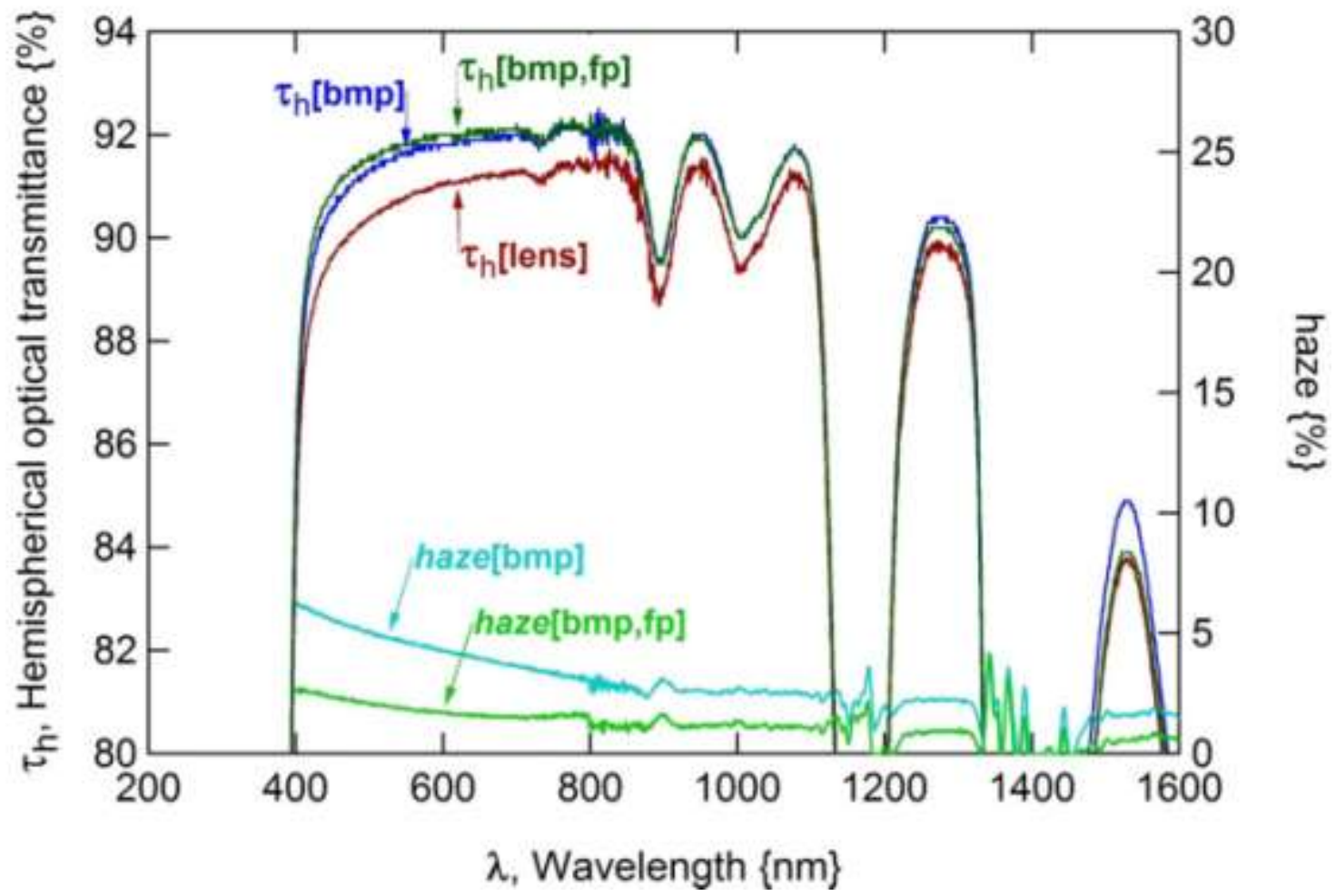

Figure 5: Spectral transmittance and optical haze for veteran lens KACST-O-01 (fielded 20 years in Riyadh). The transmittance of the original lens ("lens") is shown relative to the same lens with the faceted back surface milled and polished ("bmp"), and then subsequently polished on the front ("bmp,fp"). Measurements for the polished samples have been compensated to the nominal lens thickness of $4.51 \mathrm{~mm}$. 


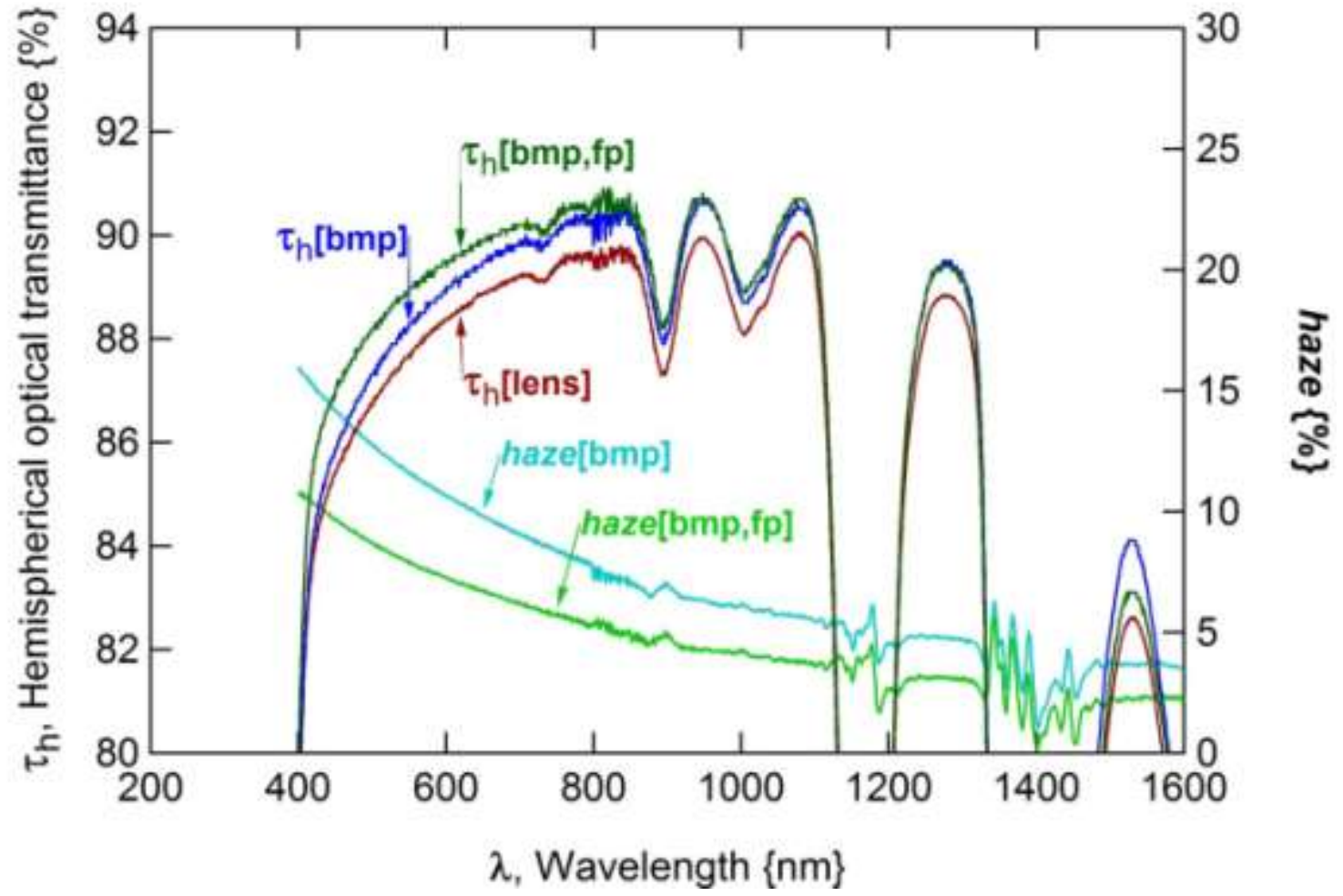

Figure 6: Spectral transmittance and optical haze for veteran lens APS-O-01 (fielded 27 years in Phoenix). The same conventions are used as in Figure 5.

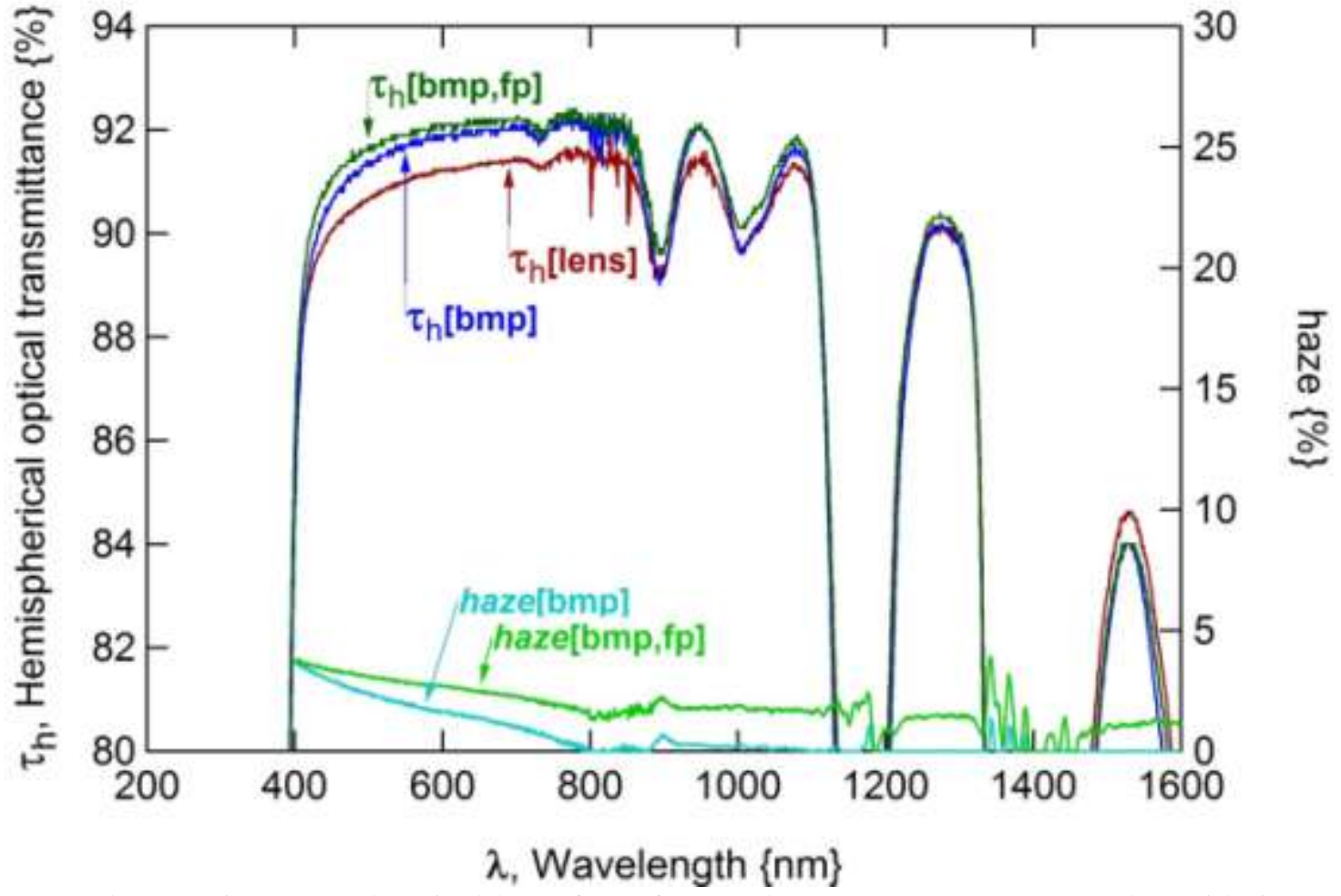

Figure 7: Spectral transmittance and optical haze for reference lens KACST-R-01 (stored outside in a stack of parquets in Riyadh). The same conventions are used as in Figure 5. 


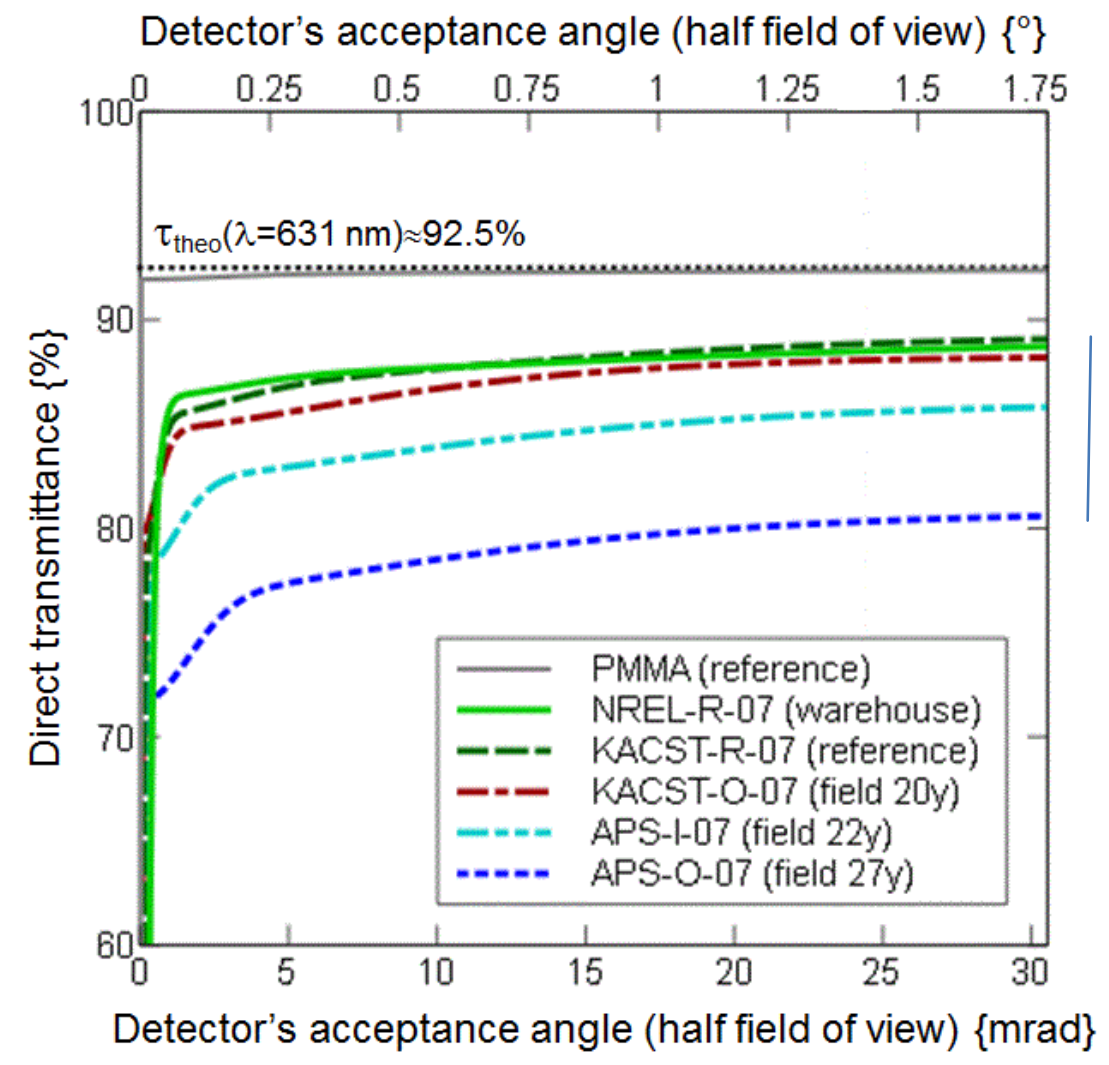

Figure 8: Direct transmittance as a function of the detector's acceptance angle for coupon specimens with the faceted surface milled and polished. The theoretical maximum transmittance for PMMA is indicated in the figure relative to a measured thick commercial sheet specimen.
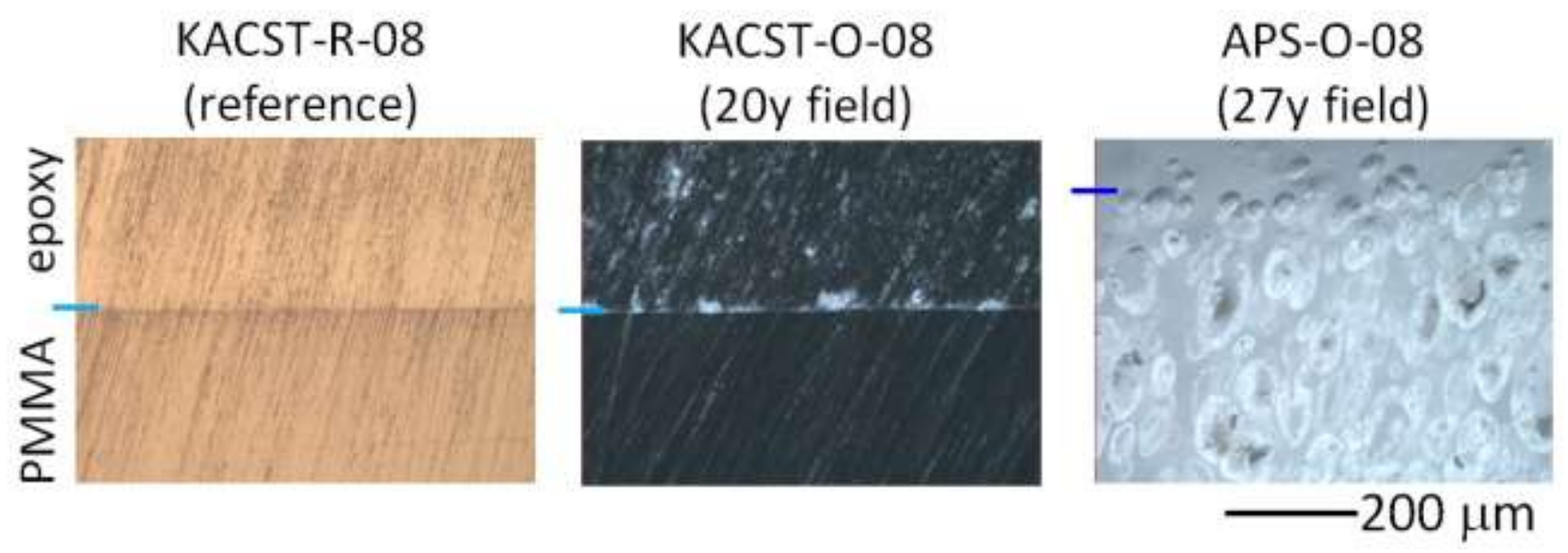

Figure 9: Comparison of the integrity of the incident surface of the lens specimens. Representative optical microscopy images are shown for the KACST lenses (reference and fielded 20y) as well as an APS lens (fielded $27 \mathrm{y})$. The location of the interface between the potting epoxy and the PMMA lens is indicated with a hash mark at the left of each image. 


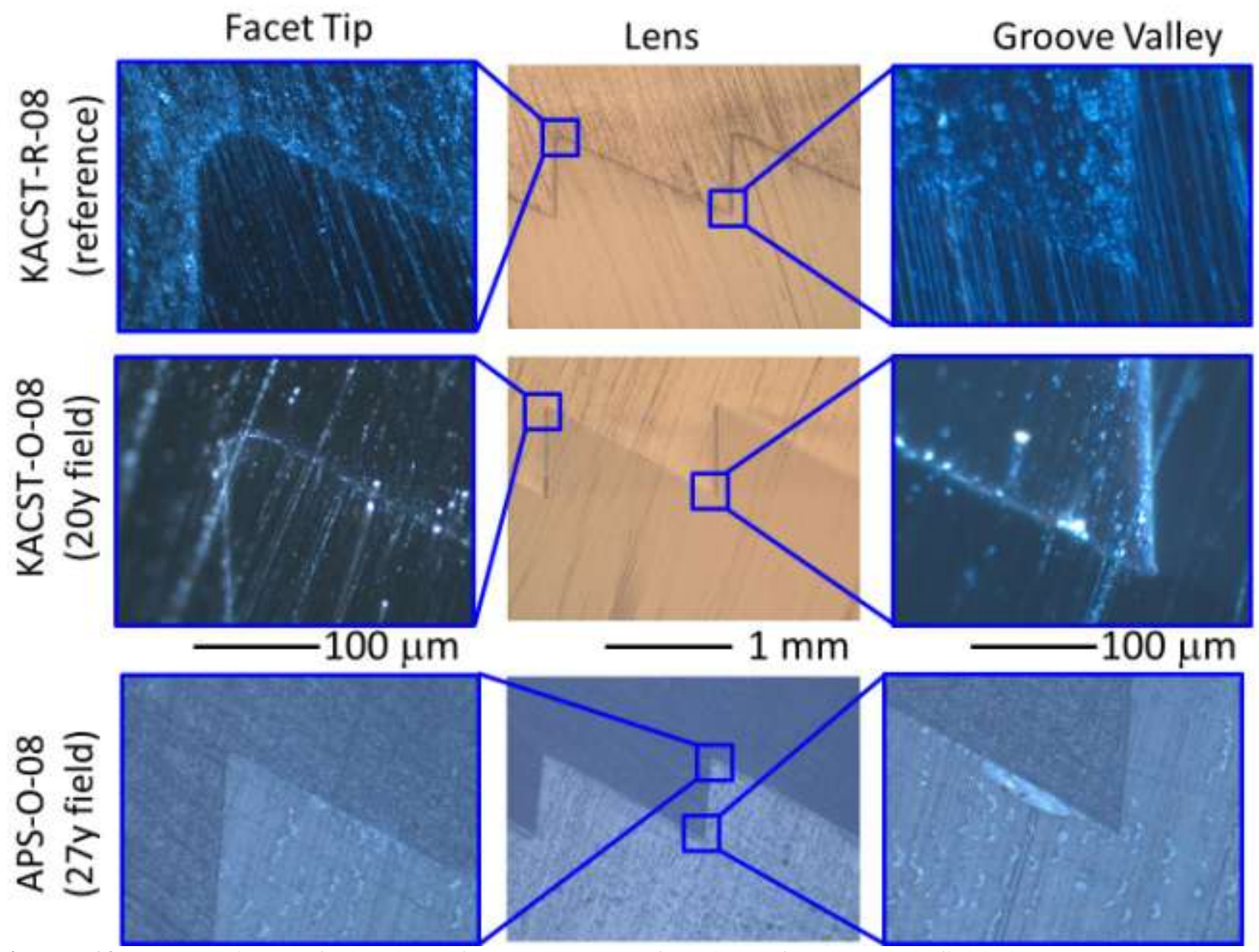

Figure 10: Comparison of the lens facet geometry for the reference and fielded KACST specimens. Representative optical miscopy images are shown for the faceted surface of the lens (center, at lesser magnification), the facet tip (left, at higher magnification), and the facet valley (right, at higher magnification). 
Tables:

Table 1: Summary of optical performance of the lens specimens. Measurements obtained at IES-UPM were performed on lens specimens using the CPV Solar Simulator. Data were obtained for the whole lenses and then for masked lenses: with the Si cell directly (no subscript); with a hot mirror (-HM); or with a cold mirror (-CM). Measurements obtained at NREL were performed on coupon specimens cut from the lenses, with the faceted surface milled and then polished. The broadband spectral measurements are analyzed for the approximate spectral bandwidths of the Si cell, hot mirror, and cold mirror, respectively. Differences on efficiency values $\left(\Delta \eta_{\mathrm{o}}\right)$ are shown in the table relative to the KACST-R-06 specimen.

\begin{tabular}{|c|c|c|c|c|c|c|c|c|c|c|c|c|}
\hline & & & & & & & & & & & \\
\hline & & & \multicolumn{7}{|c|}{ CPV SOLAR SIMULATOR } & \multicolumn{3}{|c|}{$\begin{array}{c}\text { SPECTROPHOTOMETER } \\
\text { \& ANALYSIS OF } \\
\text { HEMISPHERICAL } \\
\text { TRANSMITTANCE } \\
\end{array}$} \\
\hline $\begin{array}{c}\text { LENS } \\
\text { SPECIMEN }\end{array}$ & LOCATION & CONDITION & $\begin{array}{c}\eta_{\mathrm{o}} \\
\text { ENTIRE } \\
\text { LENS } \\
\{\%\} \\
\text { (at } 39.7 \\
\text { cm) } \\
\end{array}$ & $\begin{array}{c}f, \\
\text { FOCAL } \\
\text { DISTANCE } \\
\{\mathrm{cm}\}\end{array}$ & $\begin{array}{c}\kappa_{\mathrm{m}} \\
\text { MEAN } \\
\text { CURVATURE } \\
\left\{\mathrm{m}^{-1}\right\}\end{array}$ & $\begin{array}{c}\Delta \eta_{\mathrm{o}} \\
\text { ENTIRE } \\
\text { LENS } \\
\{\%\}\end{array}$ & $\begin{array}{c}\Delta \eta_{\mathrm{o}} \\
\text { LENS } \\
\text { CENTER } \\
\{\%\}\end{array}$ & $\begin{array}{c}\Delta \eta_{\mathrm{o}, \mathrm{HM}} \\
\text { LENS } \\
\text { CENTER } \\
\{\%\}\end{array}$ & $\begin{array}{l}\Delta \eta_{\mathrm{o}, \mathrm{CM}} \\
\text { LENS } \\
\text { CENTER } \\
\{\%\}\end{array}$ & $\begin{array}{c}\Delta \eta_{\mathrm{o}} \\
(300- \\
1150 \\
\mathrm{~nm}) \\
\{\%\}\end{array}$ & $\begin{array}{c}\Delta \eta_{\mathrm{o}} \\
(390- \\
750 \\
\mathrm{~nm}) \\
\{\%\}\end{array}$ & $\begin{array}{c}\Delta \eta_{\mathrm{o}} \\
(675- \\
1150 \\
\mathrm{~nm}) \\
\{\%\}\end{array}$ \\
\hline KACST-O-06 & Riyadh & field $20 y$ & 74 & 39.0 & -0.07 & -10 & -8 & -9 & -5 & -3 & -3 & -2 \\
\hline APS-0-06 & Phoenix & field $27 y$ & 75 & 41.1 & 0.04 & -11 & -12 & -18 & -8 & -12 & -15 & -10 \\
\hline KACST-R-06 & Riyadh & reference & 83 & 38.7 & -0.08 & $\mathrm{~N} / \mathrm{A}$ & N/A & N/A & N/A & N/A & N/A & $\mathrm{N} / \mathrm{A}$ \\
\hline NREL-W-06 & Golden & warehouse & 85 & 39.7 & -0.01 & 3 & -1 & -2 & 0 & -0.1 & -0.6 & 0.3 \\
\hline
\end{tabular}

Table 2: Summary of the surface-roughness quantification of the lens specimens (for $90 \mu \mathrm{m}$ x $90 \mu \mathrm{m}$ scan size): the average $\left(R_{\mathrm{a}}\right)$, root-mean-square $\left(R_{\mathrm{rms}}\right)$, and peak-to-valley $\left(R_{\mathrm{pv}}\right)$ roughness are reported for the AFM scans.

\begin{tabular}{|c|c|c|c|c|c|c|c|}
\hline SITE & $\begin{array}{c}\text { SITE } \\
\text { LOCATION }\end{array}$ & $\begin{array}{c}\text { SPECIMEN } \\
\text { DESIGN }\end{array}$ & $\begin{array}{c}\text { SPECIMEN } \\
\text { HISTORY }\end{array}$ & $\begin{array}{c}\text { LENS } \\
\text { CLEANING }\end{array}$ & $\begin{array}{c}R_{\mathrm{a}} \\
\{\mathrm{nm}\}\end{array}$ & $\begin{array}{c}R_{\mathrm{rms}} \\
\{\mathrm{nm}\}\end{array}$ & $\begin{array}{c}R_{\mathrm{pv}} \\
\{\mathrm{nm}\}\end{array}$ \\
\hline \hline NREL & Golden & M-M & warehouse & wet scrubbed & 86 & 118 & 1,630 \\
\hline KACST & Riyadh & $\mathrm{M}-\mathrm{M}$ & reference & spray only & 48 & 62 & 870 \\
\hline KACST & Riyadh & $\mathrm{M}-\mathrm{M}$ & field 20 y & spray only & 84 & 115 & 1,230 \\
\hline APS & Phoenix & M-M & field 27 y & spray only/ none & 64 & 85 & 1,240 \\
\hline APS & Phoenix & Intersol & field 22 y & none & 124 & 171 & 1,700 \\
\hline KACST & Riyadh & M-M & reference & milled + polished & 45 & 64 & 1,450 \\
\hline N/A & N/A & N/A & stock PMMA sheet & kraft paper removed & 11 & 16 & 280
\end{tabular}

Table 3: Summary of the prism tip $\left(R_{\mathrm{t}}\right)$ and valley $\left(R_{\mathrm{v}}\right)$ radius for the various lens specimens. Estimates given from the average \pm 1 S.D. were obtained from scanning electron and optical images of sectioned coupon specimens.

\begin{tabular}{|c|c|c|c|c|c|}
\hline SITE & $\begin{array}{c}\text { SITE } \\
\text { LOCATION }\end{array}$ & $\begin{array}{c}\text { SPECIMEN } \\
\text { DESIGN }\end{array}$ & $\begin{array}{c}\text { SPECIMEN } \\
\text { HISTORY }\end{array}$ & $\begin{array}{c}R_{\mathrm{t}} \\
\{\mu \mathrm{m}\}\end{array}$ & $\begin{array}{c}R_{\mathrm{v}} \\
\{\mu \mathrm{m}\}\end{array}$ \\
\hline \hline NREL & Golden & $\mathrm{M}-\mathrm{M}$ & warehouse & $29 \pm 1$ & $7 \pm 1$ \\
\hline KACST & Riyadh & $\mathrm{M}-\mathrm{M}$ & reference & $35 \pm 11$ & $4 \pm 3$ \\
\hline KACST & Riyadh & $\mathrm{M}-\mathrm{M}$ & field 20 y & $20 \pm 7$ & $3 \pm 1$ \\
\hline APS & Phoenix & $\mathrm{M}-\mathrm{M}$ & field 27 y & $15 \pm 2$ & $8 \pm 3$ \\
\hline APS & Phoenix & Intersol & field 22 y & $6 \pm 5$ & $4 \pm 1$ \\
\hline
\end{tabular}


Table 4: Summary of the molecular-weight characterization of the lens specimens, including the peak $\left(M_{\mathrm{p}}\right)$, number average $\left(M_{\mathrm{n}}\right)$, and weight-average $\left(M_{\mathrm{w}}\right)$ weights, as well as the polydispersity $(P D)$. The module design is distinguished between the manufacturers: Martin-Marietta (M-M) or Intersol.

\begin{tabular}{|c|c|c|c|c|c|c|c|c|}
\hline SITE & $\begin{array}{c}\text { SITE } \\
\text { LOCATION }\end{array}$ & $\begin{array}{c}\text { MODULE } \\
\text { MAKE }\end{array}$ & $\begin{array}{l}\text { SPECIMEN } \\
\text { HISTORY }\end{array}$ & $\begin{array}{c}\text { LENS } \\
\text { SURFACE }\end{array}$ & $\begin{array}{c}M_{\mathrm{p}} \\
\left\{\mathrm{g} \cdot \mathrm{mol}^{-1}\right\}\end{array}$ & $\begin{array}{c}M_{\mathrm{n}} \\
\left\{\mathrm{g} \cdot \mathrm{mol}^{-1}\right\}\end{array}$ & $\begin{array}{c}M_{\mathrm{w}} \\
\left\{\mathrm{g} \cdot \mathrm{mol}^{-1}\right\}\end{array}$ & $\begin{array}{c}P D \\
\{\text { unitless }\end{array}$ \\
\hline NREL & Golden & $M-M$ & warehouse & incident & 81,000 & 32,000 & 90,000 & 2.77 \\
\hline NREL & Golden & $M-M$ & warehouse & faceted & 109,000 & 34,000 & 102,000 & 2.99 \\
\hline KACST & Riyadh & $M-M$ & reference & incident & 51,000 & 23,000 & 59,000 & 2.64 \\
\hline KACST & Riyadh & $M-M$ & reference & faceted & 84,000 & 31,000 & 91,000 & 2.97 \\
\hline KACST & Riyadh & $M-M$ & field $20 \mathrm{y}$ & incident & 52,000 & 24,000 & 60,000 & 2.54 \\
\hline KACST & Riyadh & $M-M$ & field $20 y$ & faceted & 73,000 & 29,000 & 85,000 & 2.97 \\
\hline APS & Phoenix & $M-M$ & field $27 \mathrm{y}$ & incident & 48,000 & 20,000 & 57,000 & 2.95 \\
\hline APS & Phoenix & M-M & field $27 \mathrm{y}$ & faceted & 73,000 & 31,000 & 84,000 & 2.72 \\
\hline APS & Phoenix & Intersol & field 22 y & incident & 47,000 & 22,000 & 56,000 & 2.50 \\
\hline APS & Phoenix & Intersol & field 22 y & faceted & 65,000 & 31,000 & 76,000 & 2.44 \\
\hline all & all & all & all & $\begin{array}{l}\text { (faceted- } \\
\text { incident) }\end{array}$ & 25,000 & 7,000 & 23,000 & 0.14 \\
\hline
\end{tabular}

